\title{
Beyond valence: a meta-analysis of discrete emotions in firm-customer encounters
}

\author{
Anne-Madeleine Kranzbühler ${ }^{1}$ (1) - Alfred Zerres ${ }^{2} \cdot$ Mirella H. P. Kleijnen ${ }^{3} \cdot$ Peeter W. J. Verlegh $^{3}$
}

Received: 17 August 2018 / Accepted: 18 October 2019 / Published online: 9 December 2019

(C) The Author(s) 2019

\begin{abstract}
Distinguishing between consumers' positive and negative affect is a popular approach in both marketing research and practice, but such valence-based approaches sacrifice specificity and explanatory power. As emotions of the same valence can greatly differ with regard to their underlying appraisal patterns, they also differently affect consumer judgment and behavior. Our meta-analysis of 1035 effect sizes $(N=40,777)$ across 10 discrete emotions shows that analyzing discrete emotions clearly outperforms models of core affect (valence and arousal) when studying firm-customer encounters. Specifically, we find that the greatest impact stems from the medium-arousal emotion of gratitude and that positive emotions show consistently stronger effect sizes than do negative emotions. We also examine how effects are moderated by situational characteristics of the experience triggering the emotion. Based on our findings, we develop recommendations that help marketers identify and manage consumers' emotions more effectively.
\end{abstract}

Keywords Emotions $\cdot$ Feelings $\cdot$ Affect $\cdot$ Customer experience $\cdot$ Firm-customer encounters

\section{Introduction}

The recent rise in popularity of customer experience management (Karsh and Eyal 2015; e.g., Kranzbühler et al. 2018;

Mark Houston and John Hulland served as special issue editors for this article.

Electronic supplementary material The online version of this article (https://doi.org/10.1007/s11747-019-00707-0) contains supplementary material, which is available to authorized users.

Anne-Madeleine Kranzbühler

a.kranzbuhler@tudelft.nl

Alfred Zerres

a.zerres@uva.nl

Mirella H. P. Kleijnen

mirella.kleijnen@vu.nl

Peeter W. J. Verlegh

p.verlegh@vu.nl

1 Delft University of Technology, Landbergstraat 15, 2628, CE Delft, The Netherlands

2 University of Amsterdam, Plantage Muidergracht 12, 1018, TV Amsterdam, The Netherlands

3 Vrije Universiteit Amsterdam, De Boelelaan 1105, 1081, HV Amsterdam, The Netherlands
Lemon and Verhoef 2016; Waterhouse 2017) has sparked renewed interest in the role of emotions during firm-customer encounters. The marketing literature has since long agreed on the general importance of emotions for customer evaluations and behavior (e.g., Bagozzi et al. 1999; Richins 1997). Most of the research in this area seems to follow a purely valence-based approach (for a meta-analysis on the effects of positive and negative affect see Puccinelli et al. 2016), which is also popular in customer experience research (e.g., Finn 2005; Ou and Verhoef 2017; Tsai and Huang 2002). Several studies in marketing and consumer behavior have, however, called for a more fine-grained approach (e.g., Laros and Steenkamp 2005; Richins 1997), arguing that while a valence-based approach provides a useful summary of the effects of emotions in many settings, it sacrifices specificity and explanatory power.

Emotions of the same valence can differ greatly with regard to their underlying appraisals and therefore differentially affect consumers on many levels - from physiological reactions, to judgement, decision making, and coping strategies (e.g., Keltner and Horberg 2015; Yen and Chuang 2008). In light of this, several psychologists have emphasized the importance of studying discrete emotions (e.g., Lench et al. 2011; Lerner and Keltner 2000; Tiedens and Linton 2001; Zeelenberg et al. 2008). Indeed, evidence from the marketing domain seems to suggest that different discrete emotions also have substantially different effects on consumer judgment and behavior. Gelbrich (2010), for instance, 
found that the negatively valenced emotion of anger correlates with intentions to complain and engage in negative word-ofmouth, while frustration and helplessness do not. Grappi and colleagues (Grappi et al. 2015) similarly show that gratitude increases willingness to pay, while happiness does not.

In light of this, it seems valuable to conduct a structured and quantitative review of the different effects of discrete emotions, to examine their impact on consumer judgments and behaviors. In addition, such a review allows for a comparison of the explanatory power of the discrete emotions: how much do such emotions add to our understanding of consumers, in comparison to a broader valence-based approach?

To structure our review and analyses, we use appraisal theories of emotions (e.g., Ellsworth and Scherer 2003; Han et al. 2007; Lerner and Keltner 2000; Roseman 1991) to theorize and describe discrete emotions. We then take stock of the range of possible influences of discrete emotions during the customer experience, and provide a meta-analytical synthesis of the differential effects of discrete emotions in firmcustomer encounters on firm-relevant outcomes (i.e., consumers' evaluations, purchase, and sharing behavior). We use the appraisal tendency framework (e.g., Keltner and Horberg 2015) to explain how the underlying appraisals of discrete emotions drive these effects. For the present metaanalysis we define firm-customer encounters as any direct firm-customer interaction that takes place within a firm's online or offline channels (Meyer and Schwager 2007). ${ }^{1}$ Specifically, we examine the extent to which discrete emotions (a) vary in their strength of associations with firmrelevant outcomes, (b) vary with regard to which outcome they impact most strongly (e.g., evaluation, purchase behavior, or sharing behavior), and (c) are affected by different situational characteristics that are relevant to the studied marketing context of firm-customer encounters.

This study makes important contributions to research on emotions in firm-customer encounters and thereby to the greater field of customer experience research. First, based on a quantitative summary of the current empirical evidence, we demonstrate the additional explanatory value of considering discrete emotions. In that regard we build on previous work of Lench and colleagues (Lench et al. 2011), extending it from general psychology to the realm of marketing while simultaneously increasing the number of tested discrete emotions from four (in Lench et al. 2011) to ten. We show that explicitly modelling discrete emotions significantly adds to the explanatory power of research on firm-customer encounters. Based on a synthesis of 1035 effect sizes, representing 40,777

\footnotetext{
${ }^{1}$ Indirect interactions that take place in third-party channels such as advertising are thus beyond the scope of this study (for a meta-analysis of the effects of emotions in advertising see Brown et al. 1998).
}

research participants, we provide estimates of the varying overall effects for 10 discrete emotions.

Second, our moderator analyses extend customer experience research and previous studies on discrete emotions in marketing with conditional models that help understanding (a) how discrete emotions differently affect relevant outcome variables (i.e., evaluation, purchase behavior, sharing behavior) and (b) how the effects of discrete emotions are moderated by situational characteristics of the firm-customer encounter (e.g., personal interactions with an employee, or whether it took place in a business-to-business setting). While the meta-analytical method allows us to investigate only moderators that have been studied in the available primary studies (i.e., studies mainly featured marketing-relevant and contextual variables), our moderator analyses constitute a valuable starting point for the further understanding of the dynamics of discrete emotions in customer experience.

Third, beyond its contributions to theory, our meta-analysis is valuable for managers, who currently seem to have to rely on guesswork when trying to manage consumers' emotions (Magids et al. 2015). We provide them with research-based insights on the impact of discrete emotions on firm-relevant outcomes such as evaluation, purchase, and sharing behavior. Our results allow managers and service employees to identify the emotions with the biggest impact in a specific setting, or to make an informed judgment based on situational and consumer factors about whether or not a discrete emotion is likely to have an impact. In our discussion and implications, we will show how the most important discrete emotions can be recognized, and we provide practical guidelines for managing these emotions.

\section{Conceptual background}

Emotions are widely seen as essential for the experiences, evaluations, and actions of consumers (e.g., Bagozzi et al. 1999; Holbrook and Hirschman 1982) and can be triggered when considering, buying, or using a product or service (Cohen and Areni 1991). Emotions can be defined as a mental state of readiness that follows from (a) a change of core affect, often accompanied by substantial magnitudes on at least one of the dimensions valence and arousal, which (b) is cognitively processed through appraisals that relate the change of core affect to its cause (referent) and guide the assessment of its meaning, (c) is often expressed physiologically, and (d) may result in actions to affirm or cope with the emotion (cf., Bagozzi et al. 1999; Frijda et al. 1989; Lerner and Keltner 2000; Russell 2003).

A variety of different theoretical accounts have been used to describe the elicitation of emotions and the processes that are involved in this. As outlined in our definition above, we follow the idea that the construction of emotions starts with a 
change of core affect which is subsequently interpreted through a cognitive appraisal process (Russell 2003; Scherer and Moors 2019). Following Russell's (2003) seminal work, we define core affect as a non-reflective and always present neurophysiological state which can be described by the dimensions of valence (i.e., positive-negative; pleasure-displeasure) and arousal (i.e., activation-deactivation). Core affect is experienced consciously, but generally not directed towards an object or referent. Core affect should not be confused with the more general notion of "affect," which is often used as an umbrella term for mental processes like emotions and moods (e.g., Bagozzi et al. 1999). Please refer to Table 1 for a comparison of the different emotional terms used in this research.

Emotions differ from moods, which can be conceptualized as prolonged states of core affect with often (but not always) lower intensity than emotions, and generally lack a clear referent that triggered the state (Bagozzi et al. 1999; Frijda et al. 1989; Russell 2003). The elements and process of cognitive appraisal will be discussed in the next section, which provides an overview of cognitive appraisal theories. An overview over the process of emotion elicitation can be found in Fig. 1.

\section{Appraisal theories}

Appraisal theories of emotions (e.g., Ellsworth and Scherer 2003; Smith and Ellsworth 1985) and the appraisal-tendency framework (Han et al. 2007; Lerner and Keltner 2000; Roseman 1991; So et al. 2015) propose that each discrete emotion can be defined by a unique set of central dimensions that describe its core meaning (Lazarus 1991; Lerner and Keltner 2000; Smith and Ellsworth 1985). This set is referred to as the appraisal pattern of the emotion (cf., Han et al. 2007). Appraisals can be described as the meaning-making

Table 1 Definitions of emotional terms

\begin{tabular}{|c|c|}
\hline Term & Definition \\
\hline Emotion & $\begin{array}{l}\text { Mental state of readiness that follows from (a) a change of } \\
\text { core affect, often accompanied by substantial magnitudes } \\
\text { on at least one of the dimensions valence and arousal, } \\
\text { which (b) is cognitively processed through appraisals that } \\
\text { relate the change of core affect to its cause (referent) and } \\
\text { guide the assessment of its meaning, (c) is often expressed } \\
\text { physiologically and (d) may result in actions to affirm or } \\
\text { cope with the emotion. }\end{array}$ \\
\hline Affect & Umbrella term for mental processes like emotions and moods \\
\hline $\begin{array}{l}\text { Core } \\
\text { affect }\end{array}$ & $\begin{array}{l}\text { Non-reflective and always present neurophysiological state } \\
\text { which can be described by the dimensions valence } \\
\text { (1.e., positive-negative; pleasure-displeasure) and arousal } \\
\text { (1.e., activation-deactivation); experienced consciously, bu } \\
\text { generally not directed towards an object or referent. }\end{array}$ \\
\hline Mood & $\begin{array}{l}\text { Prolonged states of core affect with often (but not always) } \\
\text { lower intensity than emotions, and which generally lack a } \\
\text { clear referent that triggered the state. }\end{array}$ \\
\hline
\end{tabular}

process that interprets the change in core affect with regard to the specifics of the event that triggered the emotional experience and thus gives rise to different discrete emotions (Keltner and Horberg 2015).

The labels and the total number of identified appraisal dimensions varies across studies (cf., Frijda et al. 1989; Lazarus 1991; Roseman 1996; Smith and Ellsworth 1985). Usually between six (e.g., Smith and Ellsworth 1985; So et al. 2015) and nine (e.g., Roseman 1996; Van Dijk and Zeelenberg 2002) separate appraisal dimensions are used to describe discrete emotions, often including appraisals that overlap with the core affect dimensions of valence and/or arousal (e.g., Frijda et al. 1989; Ruth et al. 2002). Following this tradition, we use the core affect dimensions valence and arousal together with the following four appraisal dimensions to describe and discuss the differences between discrete emotions and their effects in firm-customer encounters. First, certainty refers to the extent to which a person is certain about the consequences of an event. For instance, the emotion anger is associated with high certainty - when a person has clear expectations about the negative consequences of the event, anger about these consequences is elicited (e.g., Lerner and Keltner 2000; Smith and Ellsworth 1985). Fear, in contrast, is associated with low certainty about the negative consequences of the event. One does not know if, how, and when the event creates harm and is therefore fearful. Second, control describes whether an entity had control over a situation or whether it was caused by circumstances. For happiness, for instance, the appraisal of control is not defining. Happiness can arise from someone's achievement (entity control) or from sunny weather (circumstantial control). However, only the appraisal that one is personally responsible for an accomplishment will lead to pride (i.e., the accomplishment has to be under entity control; Keltner and Horberg 2015). Third, responsibility indicates whether oneself or another entity was deemed responsible for a situation or event (e.g., Roseman 1996). For instance, people assess responsibility for an event (e.g., De Hooge et al. 2014; Frijda et al. 1989; Ortony et al. 1988) which separates emotions related to own actions (e.g., pride) or others' actions (e.g., gratitude). Similarly, while anger and embarrassment both may signal failure, anger usually arises from an external attribution of responsibility for this failure and embarrassment from an internal attribution (cf., Keltner et al. 1993). Finally, legitimacy focusses on perceptions of own morality in the situation (Roseman 1996; Van Dijk and Zeelenberg 2002) and, for instance, differentiates the emotions guilt and embarrassment from each other. One may perceive both emotions after own failures, but only if these failures are associated with own moral wrongdoing, one would perceive guilt.

Different appraisal patterns (i.e., discrete emotions) cause different reactions with regard to physiology, judgement, choice, and behavior (cf., Frijda et al. 1989; Keltner and Horberg 2015; Lench et al. 2011; Lerner et al. 2003). For 


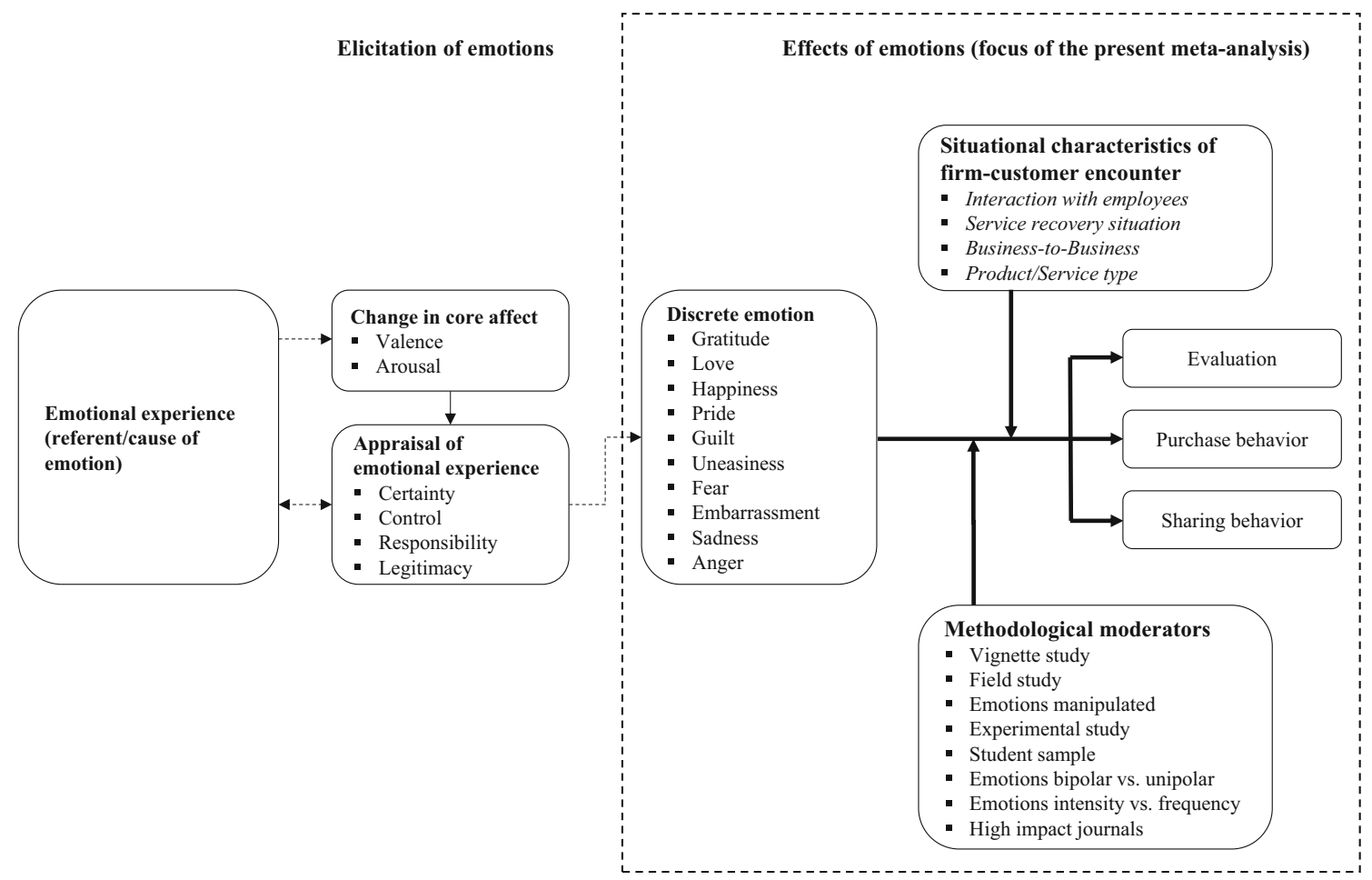

Fig. 1 Visualization of the elicitation and effects of discrete emotions

instance, while anger and fear show the same level of heart rate acceleration, anger has been found to show higher skin conductance increase, diastolic blood pressure (Roberts and Weerts 1982; Schwartz et al. 1981), as well as higher hand and head temperature (Schachter 1957; Stemmler 1989). This has been explained by anger being associated with a desire to change the situation and to fight the entity (i.e., person) that is deemed to control the situation (Frijda et al. 1989), which leads to physiological preparations for a fight, such as increased blood flow to the hands (Ekman et al. 1983). Consistently, anger has also been shown to be associated with increased activation in the left frontal hemisphere of the brain, a pattern typical for approach motivation (Harmon-Jones 2003; Harmon-Jones and Sigelman 2001). The underlying appraisals of emotions serve as signals of whether a situation threatens or serves a goal and cause specific coping reactions that either serve the goal or try to counter the threat (Frijda et al. 1989; Zeelenberg et al. 2008). Coping reactions may include, for example, approach or avoidance behavior, attention, rejection, or reactance, and have been found to differ significantly between emotions with different appraisal patterns (Duhachek 2005; Frijda et al. 1989). Importantly, although appraisals are tailored to help the individual respond to the event that evoked the emotion, they persist beyond the eliciting situation and become an "unconscious perceptual lens for interpreting subsequent judgments and choices" (Lerner and Tiedens 2006, p. 119), called appraisal tendency.

The appraisal tendency framework (e.g., Keltner and Horberg 2015; Lerner and Keltner 2001) helps understanding when and how specific emotions influence subsequent judgement and behavior. Most importantly, it argues that discrete emotions affect judgment "in a manner consistent with the emotion's underlying appraisal tendency, but only in domains related to the appraisal" (Keltner and Horberg 2015, p. 641, emphasis added). For instance, the judgement of risk should predominantly be influenced by emotions that are appraised with certainty and control (Han et al. 2007). And indeed, fear, an emotion appraised with uncertainty and lack of individual control, was related to pessimistic risk assessments (Lerner and Keltner 2000, 2001). On the other hand, fear should not affect fairness judgements, as fairness is not associated with certainty or control appraisals (Han et al. 2007). According to the appraisal tendency framework, these appraisals influence judgement and decision making in two distinct processes. On the one hand, appraisals affect the content of thought such that the appraisals that are characteristic for the emotional experience spill over and drive the salience of these appraisal dimensions in subsequent situations. For instance, anger as compared to sadness, is defined by high entity control and low circumstantial control and therefore triggers the tendency to also expect and perceive strong entity control in new situations, which in turn increases the likelihood of blaming others (Keltner et al. 1993). On the other hand, appraisals are also predicted to affect the depth of thought, or in other words the motivation to process information either heuristically or systematically (Lerner and Tiedens 2006; Tiedens and Linton 2001). For instance, Tiedens and Linton (2001; see also Bodenhausen et al. 1994) found evidence that emotions 
associated with certainty appraisals (e.g., anger, happiness) made people also feel more certain in subsequent situations than emotions associated with uncertainty appraisals (e.g., fear, sadness). In turn, the perception of certainty was associated with heuristic processing, whereas the perception of uncertainty fostered systematic processing.

The first goal of the present meta-analysis is to investigate the effects of different underlying appraisals of emotions on relevant outcomes of firm-customer encounters (such as evaluation of the firm, purchase behavior, and sharing behavior; see below for a discussion of relevant outcome variables). Building on appraisal theories of emotion and the appraisal tendency framework, we expect that emotions during firm-customer encounters will particularly affect outcome variables, if these are consistent with the domain of the underlying appraisal of the emotion. Thus, emotions that share the same association with a specific appraisal dimension, should differently affect outcome variables of firmcustomer encounters compared to emotions that are reversely (or not at all) associated with this appraisal dimension. Further, because each discrete emotion uniquely arises from a distinct appraisal pattern (e.g., Ruth et al. 2002; Smith and Ellsworth 1985; So et al. 2015) we expect that interaction patterns among multiple appraisal dimensions may give rise to varying effects of different discrete emotions beyond the main effects of appraisal dimensions (see Han et al. 2007 for a discussion of the need to understand such interaction patterns). We expect that a more fine-grained investigation of discrete emotions in firmcustomer encounters beyond mere valence and even beyond the additive main effects of valence, arousal, and the appraisal dimensions adds valuable insights and explanatory power to the understanding of the effects of emotions in firm-customer encounters. To summarize, we formulate the first three research questions (RQ) that we investigate in this meta-analysis as follows:

RQ1: Does the explicit consideration of discrete emotions add explanatory power compared to models that only consider the main effects of valence, arousal, and the appraisal dimensions when investigating the effects of emotions on outcomes of firm-customer encounters?

RQ2: Do (and if yes: how do) different appraisal dimension manifestations of emotions differently affect outcomes of firm-customer encounters across all outcome variables combined?

RQ3: Do (and if yes: how do) different discrete emotions differently affect outcomes of firm-customer encounters across all outcome variables combined?

Please note that in this first set of research questions, we focus on comparing different appraisal dimensions/different discrete emotions with each other in their effects across all outcome variables combined. Additionally, we are also interested in whether these effects vary for different firm-relevant outcomes. This will be discussed in the following.

\section{Effects of discrete emotions on different firm-relevant outcomes}

The focus of most consumer research on emotions lies in investigating how consumers' emotions impact firm-relevant outcomes such as satisfaction, loyalty, or word-of-mouth. Although correlated, we distinguish between three categories of outcomes to be able to offer more fine-grained advice to managers depending on their most important performance indicator: evaluation, purchase behavior, and sharing behavior. While consumers' evaluations (e.g., satisfaction) and purchase behaviors (e.g., repeat purchases, loyalty) toward firms have been the focus of most consumer research and managerial attention in the past, a wide range of recent studies have specifically focused on the relationship between emotions and sharing behaviors such as word-of-mouth (e.g., Berger 2014; Watson et al. 2015). Interestingly, these three outcome categories differ in a number of important characteristics which may be more or less congruent with the specific appraisal pattern of a discrete emotion. For instance, evaluations almost naturally occur after any firm-customer encounter and do not require a specific motivation or involve additional effortful action from the consumer. Because evaluations are no decisions nor behaviors (although may lead to both), they are also not associated with a certain risk position or have direct monetary consequences. Both purchase and sharing behaviors, on the other hand, involve decision-making (i.e., whether or not to buy, what to pay, whether or not to share information about the experience, what to share, etc.) and the anticipation of immediate or future action. However, they differ with regard to the associated perceived risk position - only a purchase has direct monetary consequences and is thus associated with financial and performance risks (cf., Kaplan et al. 1974), whereas sharing behavior is predominantly associated with privacy or social risks, or may not be perceived as risky at all (e.g., Eisingerich et al. 2015).

The appraisal tendency framework makes clear suggestions about how emotions affect judgement and decision making by evoking implicit cognitive predispositions when processing subsequent events that are congruent with the appraisal pattern of the emotion. Consistent with the dynamic discussed above, we for instance expect emotions that are defined by appraisals of certainty and/or control to differently affect outcome categories that are directly associated with risks (e.g., purchase behavior) than such that are not (or at least less prominently, e.g., evaluation, sharing behavior). Further, the notion that appraisal patterns spill over to subsequent situations and affect the content of thought (e.g., Han et al. 2007, see also above) suggests that the researched 
outcome categories may be differently affected by emotions with appraisal patterns that are congruent with the character of the judgement/decision at hand. For instance, concern for other consumers has been found to be one of the most important driving motivations behind sharing (electronic) word-ofmouth (Hennig-Thurau et al. 2004). This other-focus matches with the appraisals of other-responsibility of the emotion anger, which in turn may increase its effect on sharing behavior. And indeed, in a study of Gelbrich (2010) anger was found to increase negative word-of mouth behavior. As another example, purchase behavior requires effortful cost-benefit considerations, while mere evaluation does not. It thus seems reasonable, that the two categories of outcome variables should be differently affected by appraisal patterns that foster or hinder systematic processing (i.e., differently influence the depth of thought; Han et al. 2007; Tiedens and Linton 2001).

Given the simultaneous occurrence of these different appraisal tendency related processes and the notion that each emotion is defined by a unique appraisal pattern (Lazarus 1991; Lerner and Keltner 2000; Smith and Ellsworth 1985), we expect that discrete emotions, even with largely (but not completely) similar appraisal patterns, show deviating influences with regard to the different outcome variables of firm-customer encounters. While the former set of research questions focused on comparing different appraisal dimensions (RQ2) or discrete emotions (RQ3) regarding their effects across all outcome variables combined, the following set of research questions thus focusses on comparing effects of one specific appraisal dimension manifestation (RQ4) or discrete emotion (RQ5) on different individual outcome variables:

RQ4: Do (and if yes: how do) specific appraisal dimension manifestations of emotions differently affect each of the three outcome variable categories evaluation, purchase behavior, and sharing behavior?

RQ5: Do (and if yes: how do) discrete emotions differently affect each of the three outcome variable categories evaluation, purchase behavior, and sharing behavior?

\section{Potential moderators of the effects of discrete emotions}

In addition to investigating if and how discrete emotions differently affect firm-relevant outcomes (beyond the effects of valence alone), the second major goal of this meta-analysis is to identify moderators of those effects to explain the heterogeneity in effect sizes. It has been argued that different contextual influences of a decision situation may interact with cognitive appraisals of an emotion such that these become more or less activated, salient, or relevant in a situation (So et al. 2015). We argue that the specific marketing context studied in this meta-analysis-firm-customer encountersprovides such situational characteristics that can interact with the appraisal pattern of specific emotions to influence firmrelevant outcomes. We searched our set of included primary studies for potential situational characteristics such as other entities (interactions with employees), the history that led to the formation of the emotion (e.g., recovery efforts), or the context (business-to-business; search, experience, or credence goods or services). The interactions are represented in Fig. 1 and described below.

Interaction with employees The importance of consumers' interactions with employees has been recognized early in customer experience research (e.g., Bitner 1990). Human contact is an important trigger of consumers' emotions, for instance via emotional contagion processes, which can ultimately also impact firm evaluations (Pugh 2001). When interacting with an employee, this employee may replace the firm as object in the consumer's perception when assessing the responsibility for a change in core affect. It has been argued that frontline employees are representatives of the firm, and thus emotions that are triggered by interactions with employees might carry over to the firm (e.g., Beatty et al. 1996). One could even argue that direct interaction with an employee (as compared to, for instance, an online system) may increase the salience of the emotional experience (as a result of rapport between employee and customer; Gremler and Gwinner 2000) and thus in turn may also increase the influence of the respective emotion on evaluation or behavior. On the other hand, the direct interaction with an employee might also buffer the effect of elicited emotions on firm-relevant outcomes. As consumers have a person to hold responsible, they may not attribute their change in core affect to the more abstract entity-the firm. Thus, emotions that are elicited by holding another entity responsible (such as gratitude or anger) should then have a stronger effect on evaluations as well as purchase and sharing behaviors toward the firm when no interaction with an employee was involved (i.e., no person replaces the firm as responsible entity). However, when the referent of the elicited emotion included an interaction with an employee, the effect on firm-relevant outcomes may then be weakened. Although in different directions, both potential processes suggest that the influence of emotions on outcomes of firm-customer encounters may be moderated by interactions with employees.

Service recovery Scholars agree that the way firms handle service failures is of paramount importance for consumers' emotions and resulting satisfaction levels and behaviors (e.g., Tax et al. 1998). The so called Service Recovery Paradox - the observation that a customer's post-recovery satisfaction can even exceed pre-failure satisfaction-has 
been extensively researched (for a meta-analysis on the effects of service recovery see De Matos et al. 2007). One prominent explanation formulates a disconfirmation framework (McCollough et al. 2000) in which customers after a service failure compare their expectations for recovery with the perceptions of the service recovery performance. If the latter is greater than the expectations, the service recovery paradox emerges. However, this can also result in a double negative effect in case of a negative disconfirmation (i.e., when the service recovery performance does not meet or exceed the recovery expectations; Bitner et al. 1990; McCollough et al. 2000). Importantly, for the current study we are interested in the emotions after the recovery attempt of the firm (i.e., not during the original service failure). We believe that the disconfirmation framework also applies for the effects of some emotions that are felt after a firm's service recovery attempt which then may have a strengthened influence on outcomes of this firm-customer encounter. For instance, when a firm shows a service recovery effort, they accept responsibility for a service failure that has occurred. The fact that a recovery attempt is being made, might be perceived as an accommodation by the firm, which in turn may further increase the attribution of responsibility to the firm. This increased salience of firm responsibility matches with emotions that are appraised by other responsibility and should in turn strengthen the effect of these emotions. For instance, we expect the effect of gratitude to have a stronger positive influence on outcome variables after a successful recovery effort than it would have without the recovery situation. And consistently, we expect the effect of anger-another emotion appraised by other responsibility - to be even more negative if a consumer perceives anger after (or about) the recovery effort of the firm.

Business-to-business context (B2B) Organizational decision making differs from consumer decision making in many ways. Typically, B2B interactions involve more complex decisions and are simultaneously influenced by multiple actors, for instance in buying or selling teams (Lynch and De Chernatony 2004). It is often argued that in a professional setting, emotions in general play a less prominent role than for end consumers and that organizational buying is mainly driven by logic and reason (e.g., Patti et al. 1991; Webster 1995). B2B customers generally know what to expect from a firm and are often rather certain about the causes and consequences of different situations. This notion would suggest that the effect of emotions on outcomes of firm-customer encounters should be reduced in B2B contexts. On the other hand, a growing stream of literature has criticized the assumption of rationality for B2B transactions and instead postulated "that emotions drive organizational buying at every stage of the buying process" (Kemp et al. 2018, p.25; see also KadicMaglajilic et al. 2016). This leaves room for an alternative argumentation: if B2B customers-despite their better ability to interpret the situation at hand-perceive emotions during firm-customer encounters, this may even increase the perceived importance of these emotions and in turn strengthen their influence on outcome variables. In line with the appraisal tendency framework (e.g., Han et al. 2007), we would then assume that this moderation is particularly likely for emotions that are appraised by dimensions that match with aspects that differentiate B2B from B2C consumers. For instance, one likely appraisal dimension would be certainty. We can assume that B2B customers - due to their higher experience and enhanced knowledge - will be more certain about the antecedents and consequences of the encounter than B2C consumers. If they feel emotions that are appraised by high certainty (such as gratitude or anger) in such situations, these emotions would match their state of mind in this moment and may thus - in line with the appraisal tendency framework-be more influential. Please note that this argument does not exclude the possibility that B2B customers may still be less likely to perceive either of the emotions at all-however, if the encounter makes them perceive such emotions, they may release a stronger effect than for B2C consumers. We test for both competing moderating possibilities in our meta-analysis.

Product/service type Marketing literature typically distinguishes products and services based on their search, experience, and credence qualities (Darby and Karni 1973; Zeithaml 1981). For products or services high in search qualities it is easy for consumers to obtain relevant information and knowledge about the product or service prior to their purchase. For experience goods and services, in contrast, this information can only be obtained during usage, while credence qualities cannot even be assessed after a product or service has been experienced (e.g., the correctness of a medical diagnosis). Thus, the perceived risk and uncertainty for consumers is lowest with search and highest with credence goods or services (Girard and Dion 2010). As discussed earlier, emotions that are defined by certainty and control appraisals evoke implicit cognitive predispositions relevant for the assessment of risks (Lerner and Keltner 2000, 2001). We therefore argue that the effect of such emotions in firm-customer encounters likely differs if the product type induces strong perceptions of risk and uncertainty or not.

Taken together, we formulate the following research question to further address potential moderating effects in our meta-analysis: 
RQ6: Are the effects of discrete emotions on outcomes of firm-customer encounters moderated by different characteristics of the emotion-eliciting event such as (a) whether or not the event included interactions with employees, (b) took place during or after a service recovery effort, (c) took place in a business-to-business context, and (d) whether the effects depend on the product or service type?

For exploratory reasons, we additionally include a series of methodological moderators (e.g., type of study, whether emotions were manipulated or measured, sample characteristics, etc.) that may explain part of the differences in observed effect sizes. As these methodological moderators are informative but less interesting from a theoretical point of view, we keep the respective discussions short.

\section{Method}

To answer the six research questions outlined above we conducted a meta-analysis and quantitatively summarized the existing empirical evidence of the effects of discrete emotions and their appraisal patterns on outcomes of firm-customer encounters. Following previous research by Ruth and colleagues (Ruth et al. 2002; see also Richins 1997), we based our meta-analysis on the following set of 10 core consumption emotions: gratitude, love, happiness, pride, guilt, fear, uneasiness, embarrassment, sadness, and anger. ${ }^{2}$

\section{Search strategy}

To identify an encompassing set of studies investigating the effects of discrete emotions on consumer evaluations, purchase behavior, and sharing behavior, we conducted the following steps. First, we searched multiple databases (EBSCO Business Source Premier, Web of Science, Google Scholar) for studies containing the terms emotion*, feeling*, affect*, $\operatorname{mood}^{*}$, or any of the discrete emotions investigated in this meta-analysis in combination with terms suggesting a context of firm-customer encounters (customer*, consumer*, service, shopping, retail, store). Second, we checked the identified studies for potentially relevant cross-references. Third, we also checked the reference lists of previous studies offering an overview of emotions and affect in marketing (e.g., Bagozzi et al. 1999; Erevelles 1998; Laros and Steenkamp 2005;

\footnotetext{
${ }^{2}$ We used Ruth et al.'s (2002; see also Richins 1997) list of emotions because this list - or marginal variations of it - has been repeatedly used in consumption contexts and it allows us to focus when presenting our results. At the same time this selection adequately represents the observable dynamics in a more comprehensive selection of emotions. We initially followed a data-driven approach and included a larger set of emotions into our analyses. These results were less susceptible to potential selection effects based on the set of emotions. However, the results with the limited set of emotions as compared to the previous comprehensive version do not indicate that this is much of a problem.
}

Richins 1997) for any relevant empirical studies. Fourth, we inquired published and unpublished studies from researchers in the field via a relevant mailing list (AMA-ELMAR).

\section{Inclusion criteria}

Next, we checked the identified set of studies for eligibility. Given that our research focuses on the impact of discrete emotions on consumer responses to firm-customer encounters, we defined three specific criteria for inclusion: First, we only included studies of firm-customer encounters. Specifically, we only included studies that either (a) were conducted during or directly after a real firm-customer encounter, (b) asked the subjects to recall a real firm-customer encounter, or (c) featured a vignette of a fictional firm-customer encounter. Second, studies had to feature a measurement of an attitudinal or behavioral reaction to the firm-customer encounter or the organization associated (e.g., satisfaction, purchase, wordof-mouth, store, or brand image). Third, studies had to manipulate or measure discrete emotions. Studies that merely reported negative and positive affect were included as well if the applied measurement scale featured discrete emotions as items within the scale (e.g., the PANAS scale, Watson et al. 1988) and effect sizes of these single items could be derived from the information provided in the article. If this was not the case, we emailed the authors and inquired this information (we emailed 58 authors in total and also inquired if they had any unpublished work on the topic). Based on these criteria, our dataset consists of 84 manuscripts featuring 112 independent studies that yielded 1035 effect sizes (see Web Appendix A for a list of papers that form the dataset).

\section{Coding of studies}

Emotions We started by coding emotions with the labels that were used in the primary studies. As a following step-if possible - we subsumed synonymous emotions under one emotion category (as used in Ruth et al. 2002; e.g., mad under anger; for a full list of how emotions were coded see Web Appendix B). We then described all 10 emotions by their core affect (i.e., valence and arousal) and appraisal patterns (i.e., manifestations of certainty, control, responsibility, and legitimacy; see Table 2). To do so, we carefully combined the results of prior empirical studies on appraisal manifestations (Frijda et al. 1989; Han et al. 2007; Lerner and Keltner 2000, 2001, Roseman 1991, 1996; Russell 1980; Russell and Feldman Barrett 1999; Ruth et al. 2002; Smith and Ellsworth 1985; Van Dijk and Zeelenberg 2002). Some of those studies readily reported discrete emotions' appraisal manifestations categorized as high or low (e.g., Frijda et al. 1989; Ruth et al. 2002). In those cases, we applied the same manifestations. For other studies that reported average appraisal scores per emotion (e.g., Han et al. 2007; Van Dijk 
and Zeelenberg 2002), we categorized mean scores above the scale midpoint as high and below as low. As a last step, we compared the appraisal scores from the different sources and rated appraisals as high (low) when the majority of scores were high (low). If previous research consistently indicated so and the empirical results did not show a clear manifestation of the appraisal for the emotion (i.e., scores that did not substantially deviate from the scale midpoints and/or showed high variance), we categorized the respective appraisal as not characteristic for a specific discrete emotion (indicated as "_" in Table 2; cf., Frijda et al. 1989).

Outcome variables We categorized firm-relevant outcome variables into evaluation, purchase behavior, and sharing behavior. We subsumed variables such as satisfaction, perceived service quality, and attitudes toward the encounter under evaluation ( $\mathrm{k}_{\text {evaluation }}=511$ ), variables such as spending and repurchase under purchase behavior $\left(\mathrm{k}_{\text {purchase behavior }}=391\right)$, and complaining and word-of-mouth intentions under sharing behavior $\left(\mathrm{k}_{\text {sharing }}=133\right.$; see Web Appendix B for the full categorization). The sharing behavior category featured some reversely coded variables (e.g., positive or negative word-ofmouth). To account for this, we recoded the effect sizes for the negatively coded variables so that a positive correlation coefficient represents a positive outcome for the firm (i.e., an increase in positive sharing behavior or a decrease in negative sharing behavior). This is in line with the evaluation and purchase behavior outcomes, where a positive correlation coefficient also means an increase in positive evaluations or purchase behaviors that benefit the firm.

Moderators Several (mostly dummy-coded) moderator variables were coded from the studies. In cases with incomplete information our coding was true to the existence of the moderator variable of interest such that only cases that undoubtedly feature the respective study characteristic were coded as 1 , but 0 if no information about this study characteristic could be derived from the paper (i.e., we potentially underestimate the true effect of the moderator variable). Interaction with employees was coded 1 only if an interaction with an employee was explicitly described in a vignette, recently experienced, or explicitly asked to recall, in all other cases it was coded $0\left(\mathrm{k}_{\text {interaction with employee }}=266 ; \mathrm{k}_{\text {other inter- }}\right.$ action $=769)$. The same approach was taken for service recovery $\left(\mathrm{k}_{\text {service recovery }}=41 ; \mathrm{k}_{\text {no service recovery }}=994\right)$, and Business-to-business $(B 2 B)$ context $\left(\mathrm{k}_{\mathrm{B} 2 \mathrm{~B}}=198 ; \mathrm{k}_{\mathrm{no}}\right.$ В2B $=$ 837). Product/service type was coded categorically as either search, experience, or credence $\left(\mathrm{k}_{\text {search }}=78 ; \mathrm{k}_{\text {experience }}=\right.$ $619 ; \mathrm{k}_{\text {credence }}=217$ ) in line with the definitions and examples provided in Darby and Karni (1973) and Zeithaml (1981).

\section{Computation and integration of effect sizes}

We chose correlation coefficients as the measure of effect size, because the majority of studies in our dataset featured them. Further, most studies did not manipulate emotions but measured them on continuous scales. Thus, correlation coefficients constitute suitable effect sizes for our meta-analysis as they capture the continuous nature of discrete emotions and their consequences (i.e., evaluation, purchase behavior, and sharing behavior). If studies reported regression coefficients only, we transformed them to correlation coefficients based on the formula by Peterson and Brown (2005). Other conversions were based on Borenstein et al. (2013). Next, we corrected all correlation coefficients for systematic variance caused by

Table 2 Appraisal profiles of discrete emotions in primary studies

\begin{tabular}{|c|c|c|c|c|c|c|}
\hline Emotions & $\begin{array}{l}\text { Valence } \\
\text { positive } 1 \\
\text { negative } 0\end{array}$ & $\begin{array}{l}\text { Arousal } \\
\text { low }-1 \\
\text { medium } 0 \\
\text { high } 1\end{array}$ & $\begin{array}{l}\text { Certainty } \\
\text { certain } 1 \\
\text { uncertain } 0\end{array}$ & $\begin{array}{l}\text { Control } \\
\text { entity } 1 \\
\text { circumstances } 0\end{array}$ & $\begin{array}{l}\text { Responsibility } \\
\text { self } 1 \\
\text { other } 0\end{array}$ & $\begin{array}{l}\text { Legitimacy } \\
\text { morally right } 1 \\
\text { morally wrong } 0\end{array}$ \\
\hline Gratitude & 1 & 0 & 1 & 1 & 0 & - \\
\hline Love & 1 & 1 & 1 & 1 & 0 & - \\
\hline Happiness & 1 & 1 & 1 & - & - & 1 \\
\hline Pride & 1 & 1 & 1 & 1 & 1 & 1 \\
\hline Guilt & 0 & -1 & - & 1 & 1 & 0 \\
\hline Uneasiness & 0 & 0 & 0 & - & - & - \\
\hline Fear & 0 & 1 & 0 & 0 & - & - \\
\hline Embarrassment & 0 & -1 & - & - & 1 & - \\
\hline Sadness & 0 & -1 & 0 & 0 & - & - \\
\hline Anger & 0 & 1 & 1 & 1 & 0 & 1 \\
\hline
\end{tabular}

Appraisals according to findings from Feldman Barrett and Russell (1998), Frijda et al. (1989), Han et al. (2007), Lerner and Keltner (2000, 2001), Roseman (1991, 1996), Roseman et al. (1990), Russell (1980), Russell and Feldman Barrett (1999), Ruth et al. (2002), Smith and Ellsworth (1985), van Dijk and Zeelenberg (2002), as well as own study 
unreliable measures and transformed them to Fisher z-scores. The reliability-adjusted Fisher z-scores were then weighed with their inverse variance in order to give more weight to more precise effect size estimates (Borenstein et al. 2013). Finally, effect sizes were transformed back to correlation coefficients for presentation.

Studies in our dataset largely varied in terms of participants, settings, and methods. We thus chose to estimate random-effects models as those models do not assume identical true effect sizes across studies. Instead, random-effects models assume effect sizes to be distributed around a true mean value (Borenstein et al. 2013). Further, the majority of manuscripts produced more than one effect size: often manuscripts featured several studies that, in turn, produced effect sizes for several discrete emotions and per discrete emotion correlation coefficients for different outcome variables or moderators. To account for this nested nature of effect sizes (first level: effect sizes; second level: studies; third level: manuscripts), we conducted our meta-analysis based on multilevel (i.e., three-level) models (e.g., Konstantopoulos 2011). We followed the procedure for multilevel meta-analyses as described in Knoll and Matthes (2017). The resulting equations per level look as follows:

$\gamma_{\mathrm{i}}=\lambda_{\mathrm{i}}+\mathrm{e}_{\mathrm{i}}($ first level : within-study model)

$\lambda_{\mathrm{i}}=\mu_{\mathrm{i}}+\mathrm{u}_{\mathrm{i}}$ (second level : within-manuscript/between-study model)

$\mu_{\mathrm{i}}=\beta_{\mathrm{i}}+\mathrm{a}_{\mathrm{i}}$ (third level : between-manuscript model $)$

Combined into one equation our models are described by:

$\gamma_{i}=\beta_{i}+e_{i}+u_{i}+a_{i}$

Observed effect sizes $\left(\gamma_{\mathrm{i}}\right)$ are thus predicted from the average population effect $\left(\beta_{\mathrm{i}}\right)$ as well as a sampling variance component $\left(\mathrm{e}_{\mathrm{i}}\right)$, a within-manuscript / between-study error $\left(\mathrm{u}_{\mathrm{i}}\right)$, and a between-manuscript error $\left(a_{i}\right)$. We used the METAFOR package to estimate our models in $\mathrm{R}$. We performed sets of analyses on an overall level, per appraisal category, and per discrete emotion.

\section{Results}

\section{Overall effect and model comparisons}

First, we assessed the overall average effect size of all emotions on the outcome variables in our dataset. Based on a multilevel meta-analytical model of the absolute values of the correlation coefficients, we find a significant average absolute effect size of all emotions combined of 0.308 (95\% CI: $0.109 ; 0.482)$. The results showed high and significant heterogeneity among effect sizes $(\mathrm{Q}(1,034)=37,606.082, p<.001)$.
Thus, it is valuable to explore this heterogeneity further (Borenstein et al. 2013). We do so by subsequently accounting for differences in (a) manifestations of appraisals (e.g., all emotions that are described by high certainty), (b) discrete emotions, (c) firm-relevant outcome variables, and (d) additional situational characteristics that are relevant to the marketing situation.

To address RQ1 and examine whether an analysis of discrete emotions has more explanatory power than purely valence- (and arousal- and appraisal-) based approaches, we estimated several nested multilevel meta-analytical models on the entire dataset (i.e., for all outcome variables combined). Model 1 included only the valence of emotions as a predictor, while Model 2 included valence and arousal and the interaction of the two variables. Model 3 additionally included the appraisal profiles and Model 4 finally also the discrete emotions as predictors. Likelihood ratio tests suggest that Model 4 (which includes the discrete emotions as predictors) outperforms the valence model (Model $1 ; \chi^{2}(11)=75.45>$ critical value $(\mathrm{CV}) 31.26, p<.001)$, the valence and arousal model (Model 2; $\left.\chi^{2}(8)=60.39>\operatorname{CV} 26.13, p<.001\right)$, as well as the valence, arousal, and appraisal model (Model 3; $\chi^{2}(2)=$ $19.22>$ CV 13.82, $p<.001)$.

\section{Results per appraisal manifestation: Average effects (RQ2)}

We next analyzed whether the average effect sizes on all outcome variables vary depending on different manifestations of valence, arousal, and the included four appraisals (i.e., control, responsibility, certainty, legitimacy). For this, we conducted several multilevel meta-analyses (including one variable at a time as predictor) on the absolute effect sizes. ${ }^{3}$ Importantly, we find that the average effect size for positive emotions $(0.464 ; 95 \%$ CI: $0.289,0.610)$ is larger than that for negative emotions $(0.203 ; 95 \% \mathrm{CI}:-0.025$, 0.412 ; omnibus Wald-type test ${ }^{4}$ : $\mathrm{Q}(1)=7.386, p=.007$; see Table 3). Further, a significant positive average effect size was found for emotions that are high in certainty $(0.401 ; 95 \%$ CI: $0.226,0.552)$ and emotions high in control (0.352; 95\% CI: $0.204,0.485)$ but not for emotions low in certainty $(0.153 ; 95 \% \mathrm{CI}:-0.132,0.414 ; \mathrm{Q}(1)=6.119$, $p=.013)$ or control $(0.127 ; 95 \% \mathrm{CI}:-0.173,0.405 ; \mathrm{Q}$ $(1)=4.551, p=.003)$. Lastly, significant positive average effect sizes were only found for medium- $(0.370 ; 95 \% \mathrm{CI}$ : $0.149,0.556)$ and high-arousal emotions $(0.333 ; 95 \% \mathrm{CI}$ : $0.130,0.509)$ but not for low-arousal emotions $(0.162$; 95\% CI: $-0.102,0.404$; Q $(2)=5.841, p=.054)$.

\footnotetext{
3 To account for the potentially high impact of valence.

${ }^{4}$ Cochran Q-test of moderation.
} 
Results per appraisal combination/discrete emotion: Average effects (RQ3)

First, in order to inspect the average effect sizes per discrete emotion, we split the data into sub-samples for each discrete emotion and conducted multiple multilevel metaanalyses. Average effects vary substantially even among emotions with the same valence (Table 4). Effect sizes for positive emotions range (highest to lowest) from 0.688 (95\% CI: $-0.023 ; 0.937)$ for gratitude to 0.174 (95\% CI: $0.027 ; 0.314$ ) for pride. Similarly, effect sizes for negative emotions range from -0.278 (95\% CI: $-0.427 ;-0.115$ ) for anger to $0.074(95 \% \mathrm{CI}:-0.100 ; 0.242)$ for guilt. Interestingly, we only found consistent significant effects for four out of ten emotions (i.e., love, happiness, pride, anger), suggesting the importance of moderator analyses. In line with this, even after splitting the sample into subsamples the effects of all discrete emotions are still characterized by high levels of residual heterogeneity with significant Q-statistics (see Table 4 for a full overview).

A very high fail-safe $\mathrm{N}(967,593 ; p<.001$; calculated with the Rosenthal approach) suggests that publication bias might not be a serious issue in our dataset. Calculations of the fail-safe Ns per discrete emotion (see Table 4) suggest the same. However, these results should be interpreted with caution, as no other methods to assess publication bias for multilevel meta-analyses are available yet.

In the next step we further investigate the heterogeneity of effect sizes between and within studies, and analyze which marketing relevant characteristics of the emotioneliciting situation might moderate the effects of discrete emotions. To do so, we first assess whether emotions affect the three classes of outcome variables differently (evaluation, purchase behavior, sharing behavior).

\section{Does the impact of emotions vary for different firm-relevant outcomes? (RQ4 and RQ5)}

To address RQ4 and test whether the average effect sizes of emotions vary between different outcome variables, we started with estimating a meta-analytical model on the appraisal level. As Fig. 2 shows, we mainly find significant average effects for evaluation and sharing behavior, but only a few significant effects on purchase behavior on the level of discrete emotions. The same key finding applies to the appraisal level. Specifically, we find a significant difference for negative emotions, which have significant average effects on sharing behavior $(0.387 ; 95 \% \mathrm{CI}$ : $0.269,0.492)$ and evaluation $(0.231 ; 95 \% \mathrm{CI}:-0.001$, $0.440)$, but not on purchase behavior $(0.138 ; 95 \% \mathrm{CI}$ : $-0.049,0.315)$. Furthermore, our results suggest the same pattern for emotions described by low levels of arousal as well as emotions with low certainty and low legitimacy. All three types of emotions have significant effects for sharing behavior (low arousal: 0.343 ; 95\% CI: 0.208 , 0.466 ; low certainty: 0.336 ; $95 \%$ CI: $0.210,0.453$; low legitimacy: $0.543 ; 95 \% \mathrm{CI}: 0.343,0.697)$ and evaluation (low arousal: $0.181 ; 95 \%$ CI: $0.002,0.349$; low certainty: 0.170 ; 95\% CI: $-0.015,0.345$; low legitimacy: 0.189 ; 95\% CI: $0.039,0.331$ ) but not for purchase behavior (low arousal: 0.112 ; 95\% CI: $-0.035,0.253$; low certainty: 0.115 ; $95 \%$ CI: $-0.030,0.256$; low legitimacy: 0.125 ; $95 \%$ CI: $-0.087,0.327)$. Table 5 shows the results for all other appraisal manifestations.

As a next step and to address RQ5, we repeated the analyses on the discrete emotion level. As can be obtained from Table 6 and Fig. 2, the average effect sizes of gratitude, love, and pride were significantly stronger for evaluation (gratitude: 0.752 ; 95\% CI: 0.142, 0.948; love: $0.689 ; 95 \%$ CI: $0.577,0.775$; pride: $0.302 ; 95 \%$ CI: $0.123,0.462$ ) than for purchase behavior (gratitude: 0.500 ; 95\% CI: $-0.275,0.881$; Q $(2)=5.141, p=.076$; love: 0.433 ; $95 \%$ CI: $0.261,0.578$; Q $(1)=7.627$, $p=.006$; pride: 0.065 ; $95 \%$ CI: $-0.123,0.248$; Q (1) $=$ $5.487, p=.006)$. The estimates for sharing behaviors did not significantly differ from both evaluation and purchase behavior. We further found that guilt showed stronger average effect sizes for sharing $(0.543 ; 95 \%$ CI: 0.282 , $0.730)$ than for purchase behavior $(-0.013 ; 95 \% \mathrm{CI}$ : $-0.273,0.249)$ and evaluation $(0.044 ; 95 \%$ CI: -0.119 , 0.205; Q $(1)=10.937, p=.004)$.

\section{Further moderator analyses (RQ6)}

To analyze the moderating effects of the different situational characteristics, we conducted a series of subgroup analyses per discrete emotion (Table 7; subgroup analyses on the appraisal level can be obtained from Web Appendix C).

Interaction with employees We find that the effect of guilt significantly differed between interactions involving and not involving an employee. Specifically, we find a positive significant average effect size for guilt for interactions with employees $(0.365 ; 95 \% \mathrm{CI}: 0.067,0.603)$, but not for other interactions $(0.030 ; 95 \% \mathrm{CI}:-0.171,0.228)$.

Service recovery Surprisingly, we find that the effect size of pride (an emotion appraised as self-responsible) on the combined outcome variables is stronger in service recovery situations $(0.658 ; 95 \% \mathrm{CI}: 0.280,0.859)$ than in others $(0.164 ; 95 \%$ CI: $0.031,0.289)$. For uneasiness we find a positive (yet not significant) average effect size for recovery situations $(0.226$; $95 \% \mathrm{CI}:-0.107,0.512)$ and a 
Table 3 Average effects of different appraisal manifestations on outcome variables (absolute effect sizes)

Appraisal Omnibus test of moderation

$\mathrm{Q}(\mathrm{df}) \mathrm{p}$ value $\mathrm{k}$ Estimate high/positive $\mathrm{p}$ value $\mathrm{k}$ Estimate low/negative $\mathrm{p}$ value $\mathrm{k}$ Estimate medium $\mathrm{p}$ value

\begin{tabular}{llllllllllll}
\hline Valence & $\mathbf{7 . 3 8 6}(\mathbf{1})$ & $\mathbf{0 . 0 0 7}$ & 401 & 0.464 & $<.001$ & 634 & 0.203 & 0.080 & \\
Control & $\mathbf{4 . 5 5 1}(\mathbf{1})$ & $\mathbf{0 . 0 3 3}$ & 361 & 0.352 & $<.001$ & 184 & 0.127 & 0.408 & \\
Responsibility & $2.665(1)$ & 0.103 & 123 & 0.166 & 0.173 & 288 & 0.368 & $<.001$ & \\
Certainty & $\mathbf{6 . 1 1 9}(\mathbf{1})$ & $\mathbf{0 . 0 1 3}$ & 607 & 0.401 & $<.001$ & 340 & 0.153 & 0.294 & \\
Legitimacy & $2.026(1)$ & 0.155 & 525 & 0.374 & $<.001$ & 38 & 0.201 & 0.078 & & \\
Arousal & $\mathbf{5 . 8 4 1}(\mathbf{2})$ & $\mathbf{0 . 0 5 4}$ & 628 & 0.333 & 0.002 & 211 & 0.162 & $<.227$ & 196 & \\
\hline
\end{tabular}

k: number of effect sizes; bold: (marginally) significant moderation effects

negative effect size for other situations $(-0.121 ; 95 \% \mathrm{CI}$ : Discussion and theoretical implications $-0.321,0.088)$.

Business-to-business (B2B) We find only one significant difference, namely for anger. Anger has a stronger negative effect in B2B settings $(-0.576$; $95 \% \mathrm{CI}:-0.777,-0.265)$ than in non-B2B settings $(-0.262 ; 95 \% \mathrm{CI}:-0.420,-0.087)$.

Product/service type Surprisingly, we did not find any significant differences with regard to the product or service type.

Methodological moderators Additionally, we analyzed the impact of various methodological moderators (e.g., student sample, high impact journals, unipolar versus bipolar measurement of emotions). The results from those subgroup analyses may be of interest to those who seek to design or interpret research on discrete emotions (see Web Appendices D and E). For instance, we find that the average effect size of anger is stronger in field than in other studies, and that the positive effect size of gratitude is stronger in low impact journals.

\section{The explanatory value of discrete emotions in firm-customer encounters (RQ1)}

The core premise of this research was that emotions are distinct and differ from each other on various important levels and thus cannot be effectively categorized into valence or valence and arousal alone. We therefore suggest that it is valuable to explicitly consider discrete emotions when studying firm-customer encounters. This notion is based on a large body of literature in psychology (e.g., Keltner et al. 1993; Lench et al. 2011; Tiedens and Linton 2001) and has also received support in more managerial work (e.g., Magids et al. 2015). Our meta-analytical synthesis of 1035 effect sizes representing 40,777 research subjects indeed reveals that the effect sizes of discrete emotions of the same valence vary substantially in magnitude, and that the consideration of discrete emotions adds significant explanatory power and precision over the sole use of valence and arousal.

Table 4 Descriptive statistics and average effects of discrete emotions on all outcome variables (separate models per emotion)

\begin{tabular}{|c|c|c|c|c|c|c|c|c|c|c|c|}
\hline \multirow[t]{2}{*}{ Emotion } & \multirow[t]{2}{*}{$\begin{array}{l}\# \\
\text { effect } \\
\text { sizes }\end{array}$} & \multirow[t]{2}{*}{ Total N } & \multirow[t]{2}{*}{$\begin{array}{l}\text { Simple } \\
\text { Average } \\
\mathrm{r}\end{array}$} & \multirow{2}{*}{$\begin{array}{l}\text { Average r } \\
\text { Adjusted } \\
\text { for } \\
\text { Reliability }\end{array}$} & \multirow[t]{2}{*}{$\begin{array}{l}\text { Sample Weighted } \\
\text { Reliability Adjusted } \\
\text { Average r }\end{array}$} & \multicolumn{2}{|c|}{$\begin{array}{l}95 \% \\
\text { Confidence } \\
\text { interval }\end{array}$} & \multirow{2}{*}{$\begin{array}{l}\text { Fail-safe } \\
\mathrm{N} \\
\text { (Rosenthal } \\
\text { approach) }\end{array}$} & \multirow[t]{2}{*}{$\begin{array}{l}\text { Q-Statistic for } \\
\text { Homogeneity } \\
\text { Test (df) }\end{array}$} & \multirow[t]{2}{*}{$\begin{array}{l}\mathrm{I}^{2} \\
\text { between } \\
\text { studies }\end{array}$} & \multirow[t]{2}{*}{$\begin{array}{l}\mathrm{I}^{2} \\
\text { within } \\
\text { studies }\end{array}$} \\
\hline & & & & & & $\begin{array}{l}\text { Lower } \\
\text { Bound }\end{array}$ & $\begin{array}{l}\text { Upper } \\
\text { Bound }\end{array}$ & & & & \\
\hline Gratitude & 41 & 10,502 & 0.519 & 0.564 & 0.688 & -0.023 & 0.937 & 91,238 & $3196.049(40)$ & 0.974 & 0.025 \\
\hline Love & 41 & 11,539 & 0.506 & 0.541 & 0.570 & 0.405 & 0.698 & 74,874 & $2238.926(40)$ & 0.050 & 0.881 \\
\hline Happiness & 284 & 117,007 & 0.375 & 0.399 & 0.431 & 0.239 & 0.590 & $2,126,007$ & $9427.522(283)$ & 0.287 & 0.575 \\
\hline Pride & 35 & 7288 & 0.162 & 0.169 & 0.174 & 0.027 & 0.314 & 2484 & 411.268 (34) & 0.000 & 0.666 \\
\hline Guilt & 38 & 7293 & 0.108 & 0.121 & 0.074 & -0.100 & 0.242 & 1036 & 624.657 (37) & 0.398 & 0.489 \\
\hline Fear & 62 & 51,078 & -0.058 & -0.060 & -0.052 & -0.291 & 0.194 & 3153 & $1054.693(61)$ & 0.098 & 0.079 \\
\hline Embarrassment & 50 & 16,637 & -0.080 & -0.084 & -0.076 & -0.391 & 0.255 & 1563 & $501.671(49)$ & 0.000 & 0.955 \\
\hline Uneasiness & 155 & 11,295 & -0.050 & -0.037 & -0.109 & -0.309 & 0.102 & 11,977 & $2667.670(154)$ & 0.245 & 0.464 \\
\hline Sadness & 123 & 46,370 & -0.159 & -0.167 & -0.145 & -0.360 & 0.085 & 35,905 & $1074.484(122)$ & 0.000 & 0.112 \\
\hline Anger & 206 & 89,619 & -0.265 & -0.282 & -0.278 & -0.427 & -0.115 & 541,425 & 9409.495 (205) & 0.000 & 0.585 \\
\hline
\end{tabular}




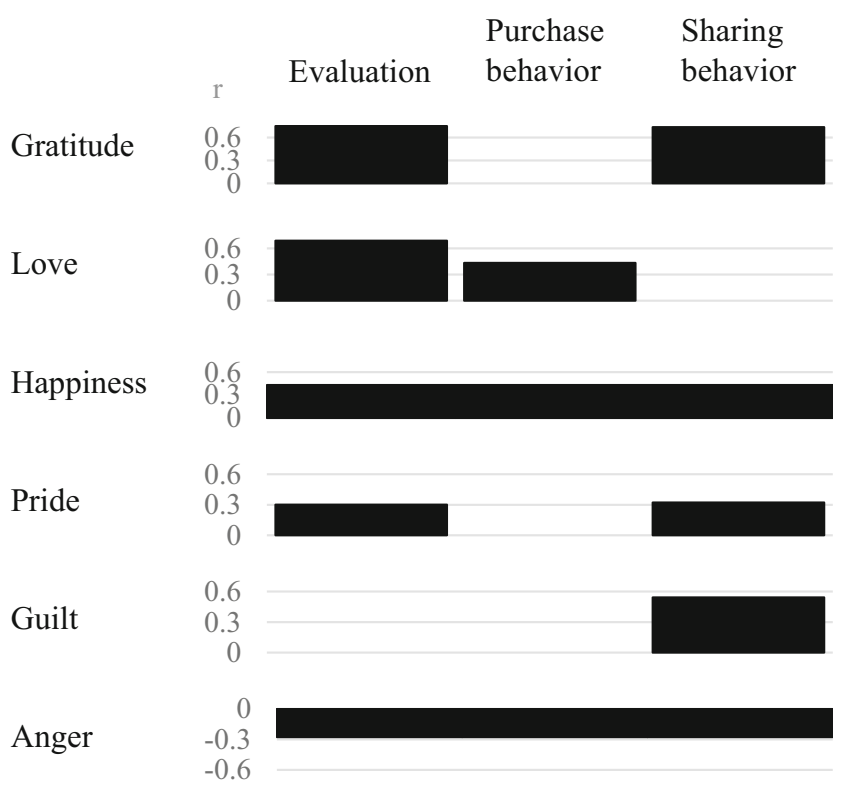

Fig. 2 Overall effect sizes of discrete emotions per outcome variable (height of bars indicates strength of effects). No significant effects were found for uneasiness, fear, sadness, and embarrassment across any of the three outcome variables

\section{The differing overall effects of appraisal dimensions in firm-customer encounters (RQ2)}

One interesting outcome of our analysis on the appraisal level is that we find a larger general average effect size for positive than for negative emotions. Thus, positive emotions in our study play a stronger and more consistent role in determining firm-relevant outcomes than negative emotions do. Interestingly, these results contribute to the scholarly discussion on whether in general positive or negative emotions have stronger effects on human judgment and behavior. Drawing from prospect theory (Kahneman and Tversky 1979), many scholars have argued and found that negative emotions have stronger effects on humans than positive emotions (e.g., Baumeister et al. 2001). Other studies have found a reversal of this effect and show the occurrence of a positivity bias (for a review see Skowronski and Carlston 1989), based on the notion that humans perceive positive information to be more diagnostic when judging the ability of an entity. Thus, positive emotions might also be perceived as being more diagnostic when evaluating a firm and, in turn, have stronger effects on firm-relevant outcome variables. The mobilizationminimization hypothesis (Taylor 1991) can serve as another possible explanation for those reversed effects: while negative events usually evoke strong immediate cognitive and emotional responses, they are also - unlike positive events-

Table 5 Effects of different appraisal manifestations per outcome variables (absolute effect sizes)

\begin{tabular}{|c|c|c|c|c|c|c|c|c|c|c|c|}
\hline \multirow[t]{2}{*}{ Appraisal } & \multicolumn{2}{|c|}{$\begin{array}{l}\text { Omnibus test of } \\
\text { moderation }\end{array}$} & \multicolumn{9}{|c|}{ Estimates different outcome variables } \\
\hline & $\mathrm{Q}(\mathrm{df})$ & $\begin{array}{l}\mathrm{p} \\
\text { value }\end{array}$ & $\mathrm{k}$ & $\begin{array}{l}\text { Estimate purchase } \\
\text { evaluation }\end{array}$ & $\begin{array}{l}\mathrm{p} \\
\text { value }\end{array}$ & $\mathrm{k}$ & $\begin{array}{l}\text { Estimate } \\
\text { behavior }\end{array}$ & $\begin{array}{l}\mathrm{p} \\
\text { value }\end{array}$ & $\mathrm{k}$ & $\begin{array}{l}\text { Estimate sharing } \\
\text { behavior }^{\mathrm{c}}\end{array}$ & $\begin{array}{l}\mathrm{p} \\
\text { value }\end{array}$ \\
\hline Valence pos & $1.938(2)$ & 0.379 & 203 & 0.538 & $<.001$ & 173 & 0.364 & 0.017 & 25 & 0.559 & 0.001 \\
\hline Valence neg & $5.597(2)$ & 0.061 & 308 & 0.231 & 0.051 & 218 & 0.138 & 0.147 & 108 & $0.387^{\mathrm{b}}$ & $<.001$ \\
\hline Control 1 & $3.487(2)$ & 0.175 & 145 & 0.438 & $<.001$ & 141 & 0.237 & 0.026 & 75 & 0.432 & $<.001$ \\
\hline Control 0 & $3.269(2)$ & 0.195 & 102 & 0.135 & 0.254 & 66 & 0.107 & 0.160 & 16 & 0.288 & $<.001$ \\
\hline $\begin{array}{l}\text { Responsibility } \\
1\end{array}$ & $3.593(2)$ & 0.166 & 67 & 0.224 & $<.001$ & 41 & 0.105 & 0.374 & 15 & 0.380 & $<.001$ \\
\hline $\begin{array}{l}\text { Responsibility } \\
0\end{array}$ & $3.163(2)$ & 0.206 & 107 & 0.464 & $<.001$ & 115 & 0.247 & 0.033 & 66 & 0.431 & $<.001$ \\
\hline Certainty 1 & $2.201(2)$ & 0.333 & 266 & 0.481 & $<.001$ & 254 & 0.303 & 0.014 & 87 & 0.455 & $<.001$ \\
\hline Certainty 0 & $5.778(2)$ & 0.056 & 192 & 0.170 & 0.071 & 112 & 0.115 & 0.121 & 36 & $0.336^{\mathrm{b}}$ & $<.001$ \\
\hline Legitimacy 1 & $2.159(2)$ & 0.340 & 222 & 0.433 & $<.001$ & 220 & 0.265 & 0.013 & 83 & 0.431 & $<.001$ \\
\hline Legitimacy 0 & $9.862(2)$ & 0.007 & 24 & 0.189 & 0.014 & 10 & 0.125 & 0.248 & 4 & $0.543^{\mathrm{a}}$ & $<.001$ \\
\hline Arousal-1 & $5.790(2)$ & 0.055 & 125 & 0.181 & 0.048 & 63 & 0.112 & 0.136 & 23 & $0.343^{b}$ & $<.001$ \\
\hline Arousal 0 & $2.300(2)$ & 0.317 & 113 & 0.518 & 0.002 & 60 & 0.198 & 0.383 & 23 & 0.498 & 0.006 \\
\hline Arousal 1 & $2.734(2)$ & 0.255 & 273 & 0.398 & 0.002 & 268 & 0.252 & 0.013 & 87 & 0.432 & $<.001$ \\
\hline
\end{tabular}

k: number of effect sizes; bold: (marginally) significant moderation effects

${ }^{\text {a }}$ Significantly different from evaluation and purchase behavior $(p<.10)$;

${ }^{\mathrm{b}}$ Significantly different from purchase behavior $(p<.10)$

${ }^{\mathrm{c}}$ Positive effects mean an increase in positive sharing or a decrease in negative sharing; negative effects mean the opposite 
Table 6 Effects of discrete emotions on different outcome variables

\begin{tabular}{|c|c|c|c|c|c|c|c|c|c|c|c|}
\hline \multirow[t]{2}{*}{ Emotion } & \multicolumn{2}{|c|}{$\begin{array}{l}\text { Omnibus test of } \\
\text { moderation }\end{array}$} & \multicolumn{9}{|c|}{ Estimates different outcome variables } \\
\hline & $\mathrm{Q}(\mathrm{df})$ & $\begin{array}{l}\mathrm{p} \\
\text { value }\end{array}$ & $\mathrm{k}$ & $\begin{array}{l}\text { Estimate } \\
\text { evaluation }\end{array}$ & $\begin{array}{l}\mathrm{p} \\
\text { value }\end{array}$ & $\mathrm{k}$ & $\begin{array}{l}\text { Estimate purchase } \\
\text { behavior }\end{array}$ & $\begin{array}{l}\mathrm{p} \\
\text { value }\end{array}$ & $\mathrm{k}$ & $\begin{array}{l}\text { Estimate sharing } \\
\text { behavior }^{\mathrm{c}}\end{array}$ & $\begin{array}{l}p \\
\text { value }\end{array}$ \\
\hline Gratitude & $5.141(2)$ & 0.076 & 23 & 0.752 & 0.022 & 14 & $0.500^{\mathrm{a}}$ & 0.195 & 4 & 0.738 & 0.015 \\
\hline Love & $7.627(1)$ & 0.006 & 21 & 0.689 & $<.001$ & 20 & $0.433^{\mathrm{a}}$ & $<.001$ & 0 & $\mathrm{n} / \mathrm{a}$ & $\mathrm{n} / \mathrm{a}$ \\
\hline Happiness & $1.213(2)$ & 0.545 & 145 & 0.485 & $<.001$ & 123 & 0.357 & 0.014 & 16 & 0.540 & 0.004 \\
\hline Pride & $5.487(2)$ & 0.064 & 14 & 0.302 & 0.001 & 16 & $0.065^{\mathrm{a}}$ & 0.501 & 5 & 0.322 & 0.022 \\
\hline Guilt & $10.937(2)$ & 0.004 & 24 & 0.044 & 0.599 & 10 & -0.013 & 0.923 & 4 & $0.543^{\mathrm{b}}$ & $<.001$ \\
\hline Fear & $0.329(2)$ & 0.848 & 30 & -0.107 & 0.245 & 28 & -0.054 & 0.832 & 4 & -0.194 & 0.205 \\
\hline Embarrassment & $4.279(2)$ & 0.118 & 29 & -0.110 & 0.279 & 15 & -0.068 & 0.672 & 6 & -0.313 & 0.011 \\
\hline Uneasiness & $0.289(2)$ & 0.865 & 90 & -0.033 & 0.860 & 46 & -0.063 & 0.653 & 19 & -0.190 & 0.420 \\
\hline Sadness & $1.183(2)$ & 0.553 & 72 & -0.138 & 0.341 & 38 & -0.138 & 0.158 & 13 & -0.270 & 0.003 \\
\hline Anger & $2.176(2)$ & 0.337 & 63 & -0.328 & $<.001$ & 81 & -0.190 & 0.096 & 62 & -0.383 & $<.001$ \\
\hline
\end{tabular}

k: number of effect sizes; $\mathrm{n} / \mathrm{a}$ : not applicable due to lack of effect sizes; bold: (marginally) significant moderation effects

${ }^{a}$ Significantly different from evaluation $(\mathrm{p}<.10)$

${ }^{\mathrm{b}}$ Significantly different from purchase behavior and evaluation $(\mathrm{p}<.10)$

${ }^{\mathrm{c}}$ Positive effects mean an increase in positive sharing or a decrease in negative sharing; negative effects mean the opposite

followed by other responses the organism uses to minimize the effects of those events. Thus, the immediate effects of negative events might be strong, while those effects often fade away quickly and can result in less pronounced responses compared to positive emotions. Our findings are in line with the latter perspective, although it is of course relevant to add that there is considerable variation among the different positive emotions.

Further, the strongest overall effects of emotions stem from the medium-arousal emotion gratitude. More generally, we do not find that the effects of medium-arousal emotions significantly differ from high-arousal emotions. This seemingly contradicts research on advertising which has demonstrated that high arousal levels polarize the effect of emotions (e.g., Gorn et al. 2001) and that high-arousal emotions have a stronger impact on word of mouth (e.g., Berger 2011; Berger and Milkman 2012). In light of this finding, it is also noteworthy that medium-level arousal emotions like gratitude seem to attract much less attention in research and practice than many high-arousal emotions (see Roberts 2005 for a discussion of brand love). Generally, the strong effect sizes of mediumarousal emotions might be explained by the tendency of humans to negatively value high levels of arousal (Skowronski and Carlston 1989). As a consequence, humans engage in counteracting processes to minimize the physiological reactions of high arousal which also makes emotions fade away rather quickly and have smaller effects on outcome variables. Marketing research and practitioners would thus do well to more strongly emphasize the importance of mediumarousal emotions.
We further find that only emotions that result from a situation that is perceived to be under the control of an entity (not under circumstantial control) show significant average effect sizes in our dataset. This suggests that attributions of responsibility do not only drive the elicitation of emotions but also their effects on firm-relevant outcomes. Incidental emotions seem to only carry over to the unrelated firm if they are appraised as being under entity control. We also find a similar pattern for emotions that are appraised with high certainty.

\section{The differing overall effects of discrete emotions in firm-customer encounters (RQ3)}

We provide an overview of the differing overall effect sizes of 10 discrete emotions (see Table 4) and show that some emotions consistently affect relevant outcome variables, while others do not. We particularly find significant overall effect sizes for a variety of positive emotions. Based on Evans' (1996) categorization of correlation coefficients, we find moderate positive average effect sizes for gratitude, love, and happiness, and significant, yet very weak effect sizes for pride. Among the negative emotions, we only find a significant yet weak effect size for anger. All other negative emotions show no significant overall effect sizes. In an absolute sense, the positive emotions gratitude, love, and happiness are the three emotions with the largest impact on firm-relevant outcomes in our meta-analysis.

Our results also provide insights in the prevalence of affect congruent and incongruent effects. While most scholars support the view that positive (negative) emotions lead to positive 
Table 7 Moderating effects of situational characteristics: Omnibus tests of moderation (for analyses on appraisal manifestation level, see Web Appendix C)

\begin{tabular}{|c|c|c|c|c|c|c|c|c|}
\hline \multirow[t]{2}{*}{ Emotion } & \multicolumn{2}{|l|}{ Interaction } & \multicolumn{2}{|c|}{ Service recovery } & \multicolumn{2}{|l|}{$\mathrm{B} 2 \mathrm{~B}$} & \multicolumn{2}{|c|}{ Product/service type } \\
\hline & $\mathrm{Q}(\mathrm{df})$ & $\mathrm{p}$ value & $\mathrm{Q}(\mathrm{df})$ & $\mathrm{p}$ value & $\mathrm{Q}(\mathrm{df})$ & $\mathrm{p}$ value & $\mathrm{Q}(\mathrm{df})$ & $\mathrm{p}$ value \\
\hline Gratitude & $2.437(1)$ & 0.119 & $0.336(1)$ & 0.562 & $\mathrm{n} / \mathrm{a}$ & $\mathrm{n} / \mathrm{a}$ & $0.331(2)$ & 0.847 \\
\hline Love & $0.018(1)$ & 0.894 & $0.217(1)$ & 0.641 & $\mathrm{n} / \mathrm{a}$ & $\mathrm{n} / \mathrm{a}$ & $2.281(2)$ & 0.320 \\
\hline Happiness & $0.095(1)$ & 0.758 & $\mathrm{n} / \mathrm{a}$ & $\mathrm{n} / \mathrm{a}$ & $0.391(1)$ & 0.532 & $1.270(2)$ & 0.530 \\
\hline Pride & $0.349(1)$ & 0.555 & $5.579(1)$ & 0.018 & $0.786(1)$ & 0.375 & $2.714(2)$ & 0.257 \\
\hline Guilt & $3.479(1)$ & 0.062 & $1.088(1)$ & 0.297 & $0.020(1)$ & 0.886 & $0.211(1)$ & 0.646 \\
\hline Fear & $0.073(1)$ & 0.787 & $\mathrm{n} / \mathrm{a}$ & $\mathrm{n} / \mathrm{a}$ & $0.018(1)$ & 0.892 & $2.435(2)$ & 0.296 \\
\hline Embarrassment & $0.065(1)$ & 0.799 & $\mathrm{n} / \mathrm{a}$ & $\mathrm{n} / \mathrm{a}$ & $0.137(1)$ & 0.711 & $0.002(1)$ & 0.967 \\
\hline Uneasiness & $0.113(1)$ & 0.736 & 3.019 (1) & 0.082 & $1.935(1)$ & 0.164 & $0.496(1)$ & 0.493 \\
\hline Sadness & $0.137(1)$ & 0.712 & $\mathrm{n} / \mathrm{a}$ & $\mathrm{n} / \mathrm{a}$ & $0.046(1)$ & 0.831 & $0.085(2)$ & 0.959 \\
\hline Anger & $0.001(1)$ & 0.982 & $0.578(1)$ & 0.447 & 3.227 (1) & 0.072 & $0.116(2)$ & 0.944 \\
\hline
\end{tabular}

$\mathrm{n} / \mathrm{a}$ : not applicable due to lack of effect sizes; bold: (marginally) significant moderation effects

(negative) outcomes (e.g., Greifeneder et al. 2011; Schwarz and Clore 1983), others have found evidence for affect incongruent effects (Goldsmith et al. 2012). Distinguishing only between positive and negative affect, Puccinelli and colleagues (Puccinelli et al. 2016) find in their meta-analysis general support for affect congruent effects while they identify single affect incongruent effects. Our findings shed more light on this by distinguishing discrete emotions. Apart from single exceptions, we find mostly affect congruent (or no) effect sizes for discrete emotions. We only identify affect incongruent effect sizes for guilt on the outcome variable of sharing behavior and for interactions with an employee. Thus, based on our meta-analytical results for 10 discrete emotions, affect incongruent effects seem to be fairly uncommon.

\section{Effects of discrete emotions on different firm-relevant outcome variables (RQ4 and RQ5) and moderators of the effects of discrete emotions (RQ6)}

Further, we find evidence that even a consideration of discrete emotions instead of valence and arousal leaves substantial heterogeneity among the observed effect sizes. By investigating potential sources of this heterogeneity, we find (a) that many emotions vary in their effects on different firmrelevant outcomes (evaluation, purchase behavior, and sharing behavior), and (b) that this dynamic is for some (but not all) emotions moderated by situational characteristics of the emotional experience, like the question whether the firm-customer encounter involves an employee of the firm, happens after a service recovery attempt, or whether the encounter happens in a $\mathrm{B} 2 \mathrm{~B}$ or $\mathrm{B} 2 \mathrm{C}$ setting.

Different firm-relevant outcomes We find evidence for differential effects on different firm-relevant outcomes for negative emotions and emotions that are appraised by uncertainty and low arousal (and for appraisals of own moral wrongdoing, however, this effect is exclusively driven by guilt and discussed below). Specifically, we find that negative emotions have a stronger effect on sharing than on purchase behavior, which is both interesting and potentially alarming. One could speculate that - despite their negative experience - consumers may often have no reasonable alternatives, and may seek to vent their negative feelings to others instead of making consequential decisions that can alter their situation (cf., HennigThurau et al. 2004). We also find that appraisals of uncertainty (which represent the emotions of uneasiness, fear, and sadness in our dataset) are associated with stronger effects on sharing behavior than on purchase behavior which is in line with our reasoning based on the appraisal tendency framework: the uncertainty appraisal carries over to subsequent situations and reduces the consumer's likelihood to engage in "risky" behaviors with direct monetary consequences (i.e., purchase behavior). While the former process would be in line with the idea that appraisals affect the content of thought in subsequent situations, one could here also speculate that this is alternatively driven by effects that alter the depth of thought (cf., Han et al. 2007). Emotions that are appraised by uncertainty have been found to activate systematic processing (Tiedens and Linton 2001), which may lead consumers to base their purchase decisions on rational considerations independent of the content of the emotion. This - although difficult to test-would be an interesting theoretical idea, as one could speculate that the effect of these uncertainty-appraised emotions is of an indirect nature - by influencing systematic processing, which however in turn renders the original content of the emotion irrelevant. Our results can only provide a first indication for the existence of such dynamics and may motivate more research to deepen our understanding of how these appraisal dimensions 
concretely relate to cognitive dimensions of the outcome categories, and in turn carry over to situations subsequent to the emotional experience (see Han et al. 2007 for a more in-depth discussion).

We also indeed find interesting differences in effects on outcome variables for some discrete emotions. The effects of the positive emotions gratitude, love, and pride are all significantly higher for evaluation than for purchase behavior. Further, guilt only shows a significant positive effect size for sharing behavior. This effect size is moreover incongruent with the valence of the emotion (i.e., negative) and does not occur for any other outcome variable. It is in line, however, with the argument that guilt is a negative emotion that occurs in response to one's own actions (and not the actions of another party/the firm) and leads to actions to ease the feeling of guilt (cf., Burnett and Lunsford 1994). When a consumer feels guilty toward a firm, she can alleviate this emotion by helping the firm with the sharing of positive information.

Moderators of the effects of discrete emotions We also indeed find some evidence that the effects of some discrete emotions on outcomes of firm-customer encounters are moderated by different contextual influences. For instance, the positive effect of guilt only seems to hold if the encounter consist of a customer-employee interaction. This is particularly interesting in the light of a recent discussion raised by So and colleagues (So et al. 2015) that argue that more research is needed to understand how motivational and situational factors interact with cognitive appraisals of the emotion. In the current case, one may speculate that the effect of the entity-controlled emotion guilt is only activated in interactions with other similar entities (i.e., another person).

As another interesting example, we find evidence that the emotion anger has a stronger negative effect in B2B as compared to B2C settings. A possible explanation may build on the notion that anger is appraised by high certainty and may be congruent with the higher experience and thus certainty that professional (B2B) customers display as compared to B2C consumers, which in turn activates the emotion for the decision context (cf., So et al., 2015). In other words, because B2B customers are more experienced and certain, they may consider felt anger as more relevant for the situation at hand compared to B2C customers, which lack the experience and certainty to interpret the relevance of their anger. Either way, these findings contradict the common belief that B2B transactions are "less emotional" than B2C transactions (Almquist et al. 2018).

\section{Managerial implications}

For managers, our results provide valuable insights into which discrete emotions are especially important in driving consumer responses. From a customer experience management perspective, it is important to consider a holistic view that explicitly includes emotional responses of consumers (Kranzbühler et al. 2018). Recent research also stresses the importance of such emotional responses in relation to factors that drive consumer engagement (e.g., Hollebeek et al. 2019; Kumar et al. 2019), to the point that they are considered more impactful than cognitive evaluations (Hollebeek et al. 2019). As Hollebeek et al. (2019) point out, emotions do not just drive purchase, but they are inherently communicative. We find substantial effects of emotions on sharing behavior, which is considered an important articulation of customer engagement (Kumar et al. 2019). In order for managers to utilize these insights it is important to adjust their marketing dashboards to include more fine-grained measures of emotions. Although it is not uncommon for firms to use emotionrelated measures (e.g., smileys to express satisfaction), these measures are typically simplistic in nature and valence oriented.

Our results suggest that it is valuable to map discrete emotions across the customer journey. The customer journey describes different touchpoints that consumers encounter throughout the entire customer experience. Current customer journey mapping practices typically tend to focus on capturing these touchpoints and the extent to which they are considered satisfactory or not or elicit a particular NPS score. In line with research on customer mindset metrics that stresses the importance of a wider set of metrics including affect (Srinivasan et al. 2010), we argue that customer journey mapping should be extended to capture an emotional "heat map." This will allow firms to gain a better understanding of how to manage the customer experience and where there are opportunities to promote specific discrete emotions or when to counter them. In formulating recommendations to manage emotions across the customer journey, we draw inspiration from Yih et al. (2019) by considering both emotion generation as well as emotion regulation as a way to influence consumer perceptions and actions.

Our first important insight in this regard is that we find consistent evidence that managers should prioritize emotion generation by triggering positive emotions over avoiding negative ones. For all outcome variables and situations, we find the strongest effect sizes stemming from the positive emotions of gratitude, love, and happiness. Emotion regulation is especially relevant with regard to negative emotions. Avoiding anger and sadness is also important for firm-relevant outcomes but as the detrimental effects of those emotions are smaller in magnitude, resources - if limited - should first and foremost be allocated to facilitating an experience that elicits gratitude, love, and happiness.

Table 8 provides hands-on guidelines for firms to manage the emotional customer journey. It presents not only the 
Table 8 Managerial implications for emotions with strongest positive and negative effects

\begin{tabular}{|c|c|c|c|}
\hline $\begin{array}{l}\text { Positive } \\
\text { emotions }\end{array}$ & Identification of emotion in the field & $\begin{array}{l}\text { Consequences - based on } \\
\text { this meta-analysis }\end{array}$ & $\begin{array}{l}\text { Managerial actions to promote } \\
\text { (emotion generation) }\end{array}$ \\
\hline Gratitude & $\begin{array}{l}\text { Brief instances of touch initiated by consumer, } \\
\text { shaking of the hand } \\
\text { (Hertenstein et al. 2006; Shiota et al. 2017) }\end{array}$ & $\begin{array}{l}\text { Strong positive effects on } \\
\text { evaluation and sharing } \\
\text { behavior }\end{array}$ & $\begin{array}{l}\text { Engage in extra effort that consumer does not expect } \\
\text { (e.g., adapt service policies, provide small favors } \\
\text { such as drinks, snacks, or price reductions; } \\
\text { Palmatier et al. 2009) }\end{array}$ \\
\hline Love & $\begin{array}{l}\text { Open-arm gestures, brief instances of touch, head tilt } \\
\text { to one side (Shiota et al. 2017) }\end{array}$ & $\begin{array}{l}\text { Strong positive effects on } \\
\text { evaluation and moderate } \\
\text { positive effects on } \\
\text { behavior }\end{array}$ & $\begin{array}{l}\text { Build relationship with customer that goes beyond } \\
\text { pure transaction (e.g., by making } \\
\text { provider-consumer interactions collaborative and } \\
\text { reciprocal; consumers should feel like interacting } \\
\text { with a friend rather than a firm; Bonchek and } \\
\text { France 2016) }\end{array}$ \\
\hline Happiness & $\begin{array}{l}\text { Raised cheeks, smiling mouth (Ekman 2007), } \\
\text { swinging of arms (Hertenstein et al. 2006) }\end{array}$ & $\begin{array}{l}\text { Moderate positive effects on } \\
\text { all outcome variables }\end{array}$ & $\begin{array}{l}\text { Implement experiential factors in the customer } \\
\text { journey and provide employees the opportunity to } \\
\text { create moments of delight that move beyond the } \\
\text { functional completion of the task at hand; use } \\
\text { 'positive design' to create customer journeys that } \\
\text { uses design principles that drive meaning and } \\
\text { create connections between people, which is an } \\
\text { important driver of happiness (Pohlmeyer 2013) }\end{array}$ \\
\hline $\begin{array}{l}\text { Negative } \\
\text { emotions }\end{array}$ & Identification of emotion in the field & $\begin{array}{l}\text { Consequences - based on } \\
\text { this meta-analysis }\end{array}$ & $\begin{array}{l}\text { Managerial actions to counter } \\
\text { (emotion regulation) }\end{array}$ \\
\hline Anger & $\begin{array}{l}\text { Antagonistic tendencies (e.g., yelling, saying nasty } \\
\text { things; Frijda et al. 1998); arms stretched out } \\
\text { frontal, high movement activity (Wallbott 1998); } \\
\text { eyebrows pulled down and together } \\
\text { (Ekman 2007) }\end{array}$ & $\begin{array}{l}\text { Weak negative effects on all } \\
\text { outcome variables } \\
\text { (but stronger in B2B) }\end{array}$ & $\begin{array}{l}\text { Empower frontline employees to deal with angry } \\
\text { customers immediately: acknowledge anger and } \\
\text { address issue immediately with clearly visible } \\
\text { recovery efforts (e.g., by providing compensations, } \\
\text { making exceptions from service policies; } \\
\text { Bougie et al. 2003) }\end{array}$ \\
\hline Sadness & $\begin{array}{l}\text { Lowered eyebrows, especially outer corners, lower } \\
\text { lip slightly pushed up, limp posture } \\
\text { (Duclos et al. 1989) }\end{array}$ & $\begin{array}{l}\text { Weak negative effect on } \\
\text { sharing behavior }\end{array}$ & $\begin{array}{l}\text { Create opportunities for consumers to share within } \\
\text { firm-owned touchpoints (Gensler et al. 2013), } \\
\text { i.e., providing consumers an opportunity to } \\
\text { regulate their emotion in a setting that is less } \\
\text { damaging to the firm. Train employees both offline } \\
\text { and online to be active listeners and to demonstrate } \\
\text { emphatic behavior. Regulating sadness can also be } \\
\text { accomplished by providing consumers more sense } \\
\text { of control (Garg and Lerner 2013), e.g., providing } \\
\text { choice options in actions that the consumer needs } \\
\text { to take in certain situations (e.g., attribute } \\
\text { selections, payment options). }\end{array}$ \\
\hline
\end{tabular}

actions that can be taken to promote or counter certain emotions, but also presents cues that enable managers and employees to recognize these emotions as they occur.

This is relevant input for the emotional journey mapping as well as for training of frontline personnel. Like consumers, employees may follow a "reasoning-forward" logic as proposed by Ong et al. (2019), and apply an appraisal-like process to inform themselves about consumers' emotions. While this is typically considered an intuitive process, employees can be trained to recognize specific cues that foretell which emotions are being generated and consequently should be regulated given the outcome that emotion is likely to cause. Following this, we provide a set of concrete actions that can be used to manage these discrete emotions, in which the focus is first and foremost on promoting gratitude, love, and happiness, and second on countering negative ones.

It is important to nuance this discussion in relation to specific outcomes that firms may strive for. These outcomes also align well with different phases in the customer journey and provide further nuance to the emotional journey mapping. Evaluation is often considered part of the earlier phases of the journey, followed by the purchase phase that is related to the actual (transactional) behavior, and a post-purchase phase that tends to include consumer communications about the purchase to others (e.g., sharing; Voorhees et al. 2017). Our metaanalysis shows how these phases differ with regard to the impact of emotions. If the focal goal is to create positive 
consumer evaluations, purchases, and sharing behavior promoting the above-mentioned positive emotions seems most valuable. Negative emotions, specifically anger, should be regulated as they do impact the different outcomes, but less so than positive emotions. Sadness is particularly relevant in relation to sharing behavior.

The importance of these findings may vary with context. Of the emotions highlighted in Table 8, anger has a stronger effect in B2B than other situations. While aggravating customers to the point of anger is never a good strategy, it is especially important to avoid this emotion in B2B settings as its effect across all outcome variables is more pronounced. Given that B2B often characterizes itself by more personal, long-term relationships, firms also have an opportunity here to focus their training of account managers specifically on signaling early signs of this emotion and how to deal with this in their specific role.

Beyond the emotions with the strongest overall effect, it is worth noting that also pride and guilt should be managed differently throughout the customer journey. Especially in those touch points where there are customer-facing employees involved, guilt is an emotion that can have positive effects on the overall outcomes. While we should be wary of suggesting managers to stimulate feelings of guilt, it is also important to note that what is typically considered a negative emotion can in fact have positive effects.

Finally, pride has a stronger effect in recovery situations than otherwise. Inducing pride in a recovery situation might be challenging for firms, as a recovery implies that something went wrong in a preceding phase of the customer journey. However, firms could consider co-created solutions as part of their recovery strategy, in which they give consumers an active role in developing the solution and thus take ownership and pride in their role. Such a strategy would call for a more principle-based (rather than a rule-based) way of working, where employees have freedom to develop such solutions together with customers.

\section{Limitations and further research}

The present meta-analysis provides an encompassing overview of the scattered literature on the firm-relevant effects of discrete emotions. However, it comes with limitations that can serve as a basis for future research. First, up to now research has very much focused on high-arousal emotions such as happiness and anger. However, our results indicate that substantial effects on firm-relevant outcomes also stem from emotions with lower arousal levels such as gratitude or sadness. Thus, future research should investigate these emotions further and shed more light on their effects and how they come about (and thus also how firms can more strategically address these in the design of service encounters). Also, our investigation was restricted to the core consumption emotions featured in Ruth et al. (2002). It could thus be that other discrete emotions that were not included in this meta-analysis would provide stronger effect sizes. At this point, we can only report the dynamic with regard to the ten emotions featured in this analysis, but we do believe that further research on this interesting area would be valuable. Another limitation related to the availability of studies is that some analyses were based on rather small numbers of effect sizes (e.g., only 41 of 1035 effect sizes involved a service recovery attempt). Thus, non-significant results should be interpreted with caution as they might also stem from a lack of statistical power.

Second, future research should further investigate the identified affect-incongruent effect of guilt as it is only based on a low number of effect sizes. The positive effect of guilt might be explainable by its special nature as a self-focused otherdirected emotion that can result in restoring behavior toward the other party (Burnett and Lunsford 1994).

Finally, future research should investigate the effects of discrete emotions over time. Based on the mobilizationminimization hypothesis (Taylor 1991), it would be interesting to see whether most or select negative emotions indeed affect short-term outcomes but that their impact quickly disappears over time. The majority of existing studies asks respondents to recall experiences or read vignettes. Those methodologies might misrepresent the levels of especially negative emotions directly after experiencing a firm-customer encounter. With the rise in popularity of mobile phones, such strong immediate emotions can easily be shared with a lot of people via social media.

Open Access This article is distributed under the terms of the Creative Commons Attribution 4.0 International License (http:// creativecommons.org/licenses/by/4.0/), which permits unrestricted use, distribution, and reproduction in any medium, provided you give appropriate credit to the original author(s) and the source, provide a link to the Creative Commons license, and indicate if changes were made.

\section{References}

Almquist, E., Cleghorn, J., \& Sherer, L. (2018). The B2B elements of value. Harvard Business Review, March-April, 72-81.

Bagozzi, R. P., Gopinath, M., \& Nyer, P. U. (1999). The role of emotions in marketing. Journal of the Academy of Marketing Science, 27, 184-206.

Baumeister, R. F., Bratslavsky, E., Finkenauer, C., \& Vohs, K. D. (2001). Bad is stronger than good. Review of General Psychology, 5, 323-370.

Beatty, S. E., Mayer, M., Coleman, J. E., Reynolds, K. E., \& Lee, J. (1996). Customer-sales associate retail relationships. Journal of Retailing, 72, 223-247.

Berger, J. (2011). Arousal increases social transmission of information. Psychological Science, 22, 891-893.

Berger, J. (2014). Word of mouth and interpersonal communication: A review and directions for future research. Journal of Consumer Psychology, 24, 586-607. 
Berger, J., \& Milkman, K. L. (2012). What makes online content viral? Journal of Marketing Research, 49, 192-205.

Bitner, M. J. (1990). Evaluating service encounters: The effects of physical surroundings and employee responses. Journal of Marketing, $54,69-82$.

Bitner, M. J., Booms, B. H., \& Tetreault, M. S. (1990). The service encounter. Diagnosing favorable and unfavorable incidents. Journal of Marketing, 54, 71-84.

Bodenhausen, G. V., Sheppard, L. A., \& Kramer, G. P. (1994). Negative affect and social judgment: The differential impact of anger and sadness. European Journal of Social Psychology, 24, 45-62.

Bonchek, M., \& France, C. (2016). Build your brand as a relationship. Harvard Business Review.

Borenstein, M., Hedges, L. V., Higgins, J. P. T., \& Rothstein, H. R. (2013). Introduction to meta-analysis. West Sussex: Wiley.

Bougie, R., Pieters, R., \& Zeelenberg, M. (2003). Angry customers don't come back, they get back: The experience and behavioral implications of anger and dissatisfaction in services. Journal of the Academy of Marketing Science, 31, 377-393.

Brown, S. P., Homer, P. M., \& Inman, J. J. (1998). Meta analysis of relationships between ad evoked feelings and responses. Journal of Marketing Research, 35, 114-126.

Burnett, M. S., \& Lunsford, D. A. (1994). Conceptualizing guilt in the consumer decision-making process. Journal of Consumer Marketing, 11, 33-43.

Cohen, J., \& Areni, C. (1991). Affect and consumer behavior. In T. S. Robertson \& H. H. Kassarjian (Eds.), Handbook of consumer behavior (pp. 188-240). Englewoord Cliffs: Prentice-Hall.

Darby, M. R., \& Karni, E. (1973). Free competition and the optimal amount of fraud. The Journal of Law and Economics, 16, 67-88.

De Hooge, I. E., Verlegh, P. W. J., \& Tzioti, S. C. (2014). Emotions in advice taking: the roles of agency and valence. Journal of Behavioral Decision Making, 27, 246-258.

De Matos, C. A., Henrique, J. L., \& Alberto Vargas Rossi, C. (2007). Service recovery paradox: a meta-analysis. Journal of Service Research, 10, 60-77.

Duclos, S. E., Laird, J. D., Schneider, E., Sexter, M., Stern, L., Van Lighten, O., \& Hiatt, F. (1989). Emotion-specific effects of facial expressions and postures on emotional experience. Journal of Personality and Social Psychology, 57, 100-108.

Duhachek, A. (2005). Coping: a multidimensional, hierarchical framework of responses to stressful consumption episodes. Journal of Consumer Research, 32, 41-53.

Eisingerich, A. B., Helen Chun, H., Liu, Y., Jia, H., \& Bell, S. J. (2015). Why recommend a brand face-to-face but not on Facebook? How word-of-mouth on online social sites differs from traditional wordof-mouth. Journal of Consumer Psychology, 25, 120-128.

Ekman, P., Levenson, R. W., \& Friesen, W. V. (1983). Autonomic nervous system activity distinguishes among emotions. Science, 221, $1208-1210$

Ekman, P. (2007). The directed facial action task. In J. A. Coan, \& J. J. B. Allen (Eds.), Handbook of emotion elicitation and assessment. (pp. 47-53). New York: Oxford University Press.

Ellsworth, P. C., \& Scherer, K. R. (2003). Appraisal processes in emotion. In R. J. Davidson, K. R. Scherer, \& H. H. Goldsmith (Eds.), Handbook of affective sciences (pp. 572-595). New York: Oxford University Press.

Erevelles, S. (1998). The role of affect in marketing. Journal of Business Research, 42, 199-215.

Evans, J. D. (1996). Straightforward statistics for the behavioral sciences. Pacific Grove: Brooks/Cole Publishing.

Feldman Barrett, L. \& Russell, J. A. (1998). Independence and bipolarity in the structure of current affect. Journal of Personality and Social Psychology, 74, 967-984.

Finn, A. (2005). Reassessing the foundations of customer delight. Journal of Service Research, 8, 103-116.
Frijda, N. H., Kuipers, P., \& ter Schure, E. (1989). Relations among emotion, appraisal, and emotional action readiness. Journal of Personality and Social Psychology, 57, 212-228.

Garg, N., \& Lerner, J. S. (2013). Sadness and consumption. Journal of Consumer Psychology, 23, 106-113.

Gelbrich, K. (2010). Anger, frustration, and helplessness after service failure: coping strategies and effective informational support. Journal of the Academy of Marketing Science, 38, 567-585.

Gensler, S., Völckner, F., Liu-Thompkins, Y., \& Wiertz, C. (2013). Managing brands in the social media environment. Journal of Interactive Marketing, 27, 242-256.

Girard, T., \& Dion, P. (2010). Validating the search, experience, and credence product classification framework. Journal of Business Research, 63, 1079-1087.

Goldsmith, K., Cho, E. K., \& Dhar, R. (2012). When guilt begets pleasure: the positive effect of a negative emotion. Journal of Marketing Research, 49, 872-881.

Gorn, G., Pham, M. T., \& Sin, L. Y. (2001). When arousal influences ad evaluation and valence does not (and vice versa). Journal of Consumer Psychology, 11, 43-55.

Grappi, S., Romani, S., \& Bagozzi, R. P. (2015). Consumer stakeholder responses to reshoring strategies. Journal of the Academy of Marketing Science, 43, 453-471.

Greifeneder, R., Bless, H., \& Pham, M. T. (2011). When do people rely on affective and cognitive feelings in judgment? A review. Personality and Social Psychology Review, 15, 107-141.

Gremler, D. D., \& Gwinner, K. P. (2000). Customer-employee rapport in service relationships. Journal of Service Research, 3, 82-104.

Han, S., Lerner, J. S., \& Keltner, D. (2007). Feelings and consumer decision making: the appraisal-tendency framework. Journal of Consumer Psychology, 17, 158-168.

Harmon-Jones, E. (2003). Clarifying the emotive functions of asymmetrical frontal cortical activity. Psychophysiology, 40, 838-848.

Harmon-Jones, E., \& Sigelman, J. (2001). State anger and prefrontal brain activity: evidence that insult-related relative left-prefrontal activation is associated with experienced anger and aggression. Journal of Personality and Social Psychology, 80, 797-803.

Hennig-Thurau, T., Gwinner, K. P., Walsh, G., \& Gremler, D. D. (2004). Electronic word-of-mouth via consumer-opinion platforms: what motivates consumers to articulate themselves on the internet? Journal of Interactive Marketing, 18, 38-52.

Hertenstein, M. J., Keltner, D., App, B., Bulleit, B. A., \& Jaskolka, A. R. (2006). Touch communicates distinct emotions. Emotion, 6, $528-533$.

Holbrook, M. B., \& Hirschman, E. C. (1982). The experiential aspects of consumption: consumer fantasies, feelings, and fun. Journal of Consumer Research, 9, 132-140.

Hollebeek, L. D., Srivastava, R. K., \& Chen, T. (2019). S-D logicinformed customer engagement: integrative framework, revised fundamental propositions, and application to CRM. Journal of the Academy of Marketing Science, 47, 161-185.

Kadic-Maglajlic, S., Vida, I., Obadia, C., \& Plank, R. (2016). Clarifying the influence of emotional intelligence on salesperson performance. Journal of Business \& Industrial Marketing, 31, 877-888.

Kahneman, D., \& Tversky, A. (1979). Prospect theory: an analysis of decision under risk. Econometrica, 47, 263-292.

Kaplan, L. B., Szybillo, G. J., \& Jacoby, J. (1974). Components of perceived risk in product purchase: a cross-validation. Journal of Applied Psychology, 59, 287-291.

Karsh, N., \& Eyal, T. (2015). How the consideration of positive emotions influences persuasion: the differential effect of pride versus joy. Journal of Behavioral Decision Making, 28, 27-35.

Keltner, D., \& Horberg, E. J. (2015). Emotion-cognition interactions. In: APA handbook of personality and social psychology, volume 1: attitudes and social cognition (pp. 623-664). Washington, DC: American Psychological Association. 
Keltner, D., Ellsworth, P. C., \& Edwards, K. (1993). Beyond simple pessimism: effects of sadness and anger on social perception. Journal of Personality and Social Psychology, 64, 740-752.

Kemp, E. A., Borders, A. L., Anaza, N. A., \& Johnston, W. J. (2018). The heart in organizational buying: marketers' understanding of emotions and decision-making of buyers. Journal of Business \& Industrial Marketing, 33, 19-28.

Knoll, J., \& Matthes, J. (2017). The effectiveness of celebrity endorsements: a meta-analysis. Journal of the Academy of Marketing Science, 45, 55-75.

Konstantopoulos, S. (2011). Fixed effects and variance components estimation in three-level meta-analysis. Research Synthesis Methods, 2 , 61-76.

Kranzbühler, A.-M., Kleijnen, M. H. P., Morgan, R. E., \& Teerling, M. (2018). The multilevel nature of customer experience research: an integrative review and research agenda. International Journal of Management Reviews, 20, 433-456.

Kumar, V., Rajan, B., Gupta, S., \& Pozza, I. D. (2019). Customer engagement in service. Journal of the Academy of Marketing Science, 47, $138-160$

Laros, F. J. M., \& Steenkamp, J.-B. (2005). Emotions in consumer behavior: a hierarchical approach. Journal of Business Research, 58, 1437-1445.

Lazarus, R. S. (1991). Cognition and motivation in emotion. American Psychologist, 46, 352-367.

Lemon, K. N., \& Verhoef, P. C. (2016). Understanding customer experience throughout the customer journey. Journal of Marketing, 80, 69-96.

Lench, H. C., Flores, S. A., \& Bench, S. W. (2011). Discrete emotions predict changes in cognition, judgment, experience, behavior, and physiology: a meta-analysis of experimental emotion elicitations. Psychological Bulletin, 137, 834-855.

Lerner, J. S., \& Keltner, D. (2000). Beyond valence: toward a model of emotion-specific influences on judgement and choice. Cognition \& Emotion, 14, 473-493.

Lerner, J. S., \& Keltner, D. (2001). Fear, anger and risk. Journal of Personality and Social Psychology, 81, 146-159.

Lerner, J. S., \& Tiedens, L. Z. (2006). Portrait of the angry decision maker: how appraisal tendencies shape anger's influence on cognition. Journal of Behavioral Decision Making, 19, 115-137.

Lerner, J. S., Gonzalez, R. M., Small, D. A., \& Fischhoff, B. (2003). Effects of fear and anger on perceived risks of terrorism: a national field experiment. Psychological Science, 14, 144-150.

Lynch, J., \& De Chernatony, L. (2004). The power of emotion: brand communication in business-to-business markets. Journal of Brand Management, 11, 403-419.

Magids, S., Zorfas, A., \& Leemon, D. (2015). The new science of customer emotions. Harvard Business Review, 76, 66-74.

McCollough, M. A., Berry, L. L., \& Yadav, M. S. (2000). An empirical investigation of customer satisfaction after service failure and recovery. Journal of Service Research, 3, 121-137.

Meyer, C., \& Schwager, A. (2007). Understanding customer experience. Harvard Business Review, February, 117-126.

Ong, D. C., Zaki, J., \& Goodman, N. D. (2019). Computational models of emotion inference in theory of mind: a review and roadmap. Topics in Cognitive Science, 11, 338-357.

Ortony, A., Clore, G. L., \& Collins, A. (1988). The cognitive structure of emotions. Cambridge: Cambridge University Press.

Ou, Y. C., \& Verhoef, P. C. (2017). The impact of positive and negative emotions on loyalty intentions and their interactions with customer equity drivers. Journal of Business Research, 80, 106-115.

Palmatier, R. W., Jarvis, C. B., Bechkoff, J. R., \& Kardes, F. R. (2009). The role of customer gratitude in relationship marketing. Journal of Marketing, 73, 1-18.
Patti, C. H., Hartley, S. W., \& Kennedy, S. L. (1991). Business-to-business advertising: a marketing management approach. Lincolnwood: NTC Business Books.

Peterson, R. A., \& Brown, S. P. (2005). On the use of beta coefficients in meta-analysis. Journal of Applied Psychology, 90, 175-181.

Pohlmeyer, A. E. (2013). Positive design: new challenges, opportunities, and responsibilities for design. In: Design, user experience, and usability. User experience in novel technological environments: second international conference (pp. 540-547). Las Vegas.

Puccinelli, N. M., Grewal, D., Motyka, S., Andrzejewski, S. A., \& Avnet, T. (2016). Effects of affect on consumer behavior: a meta-analytic integration. Marketing Science Institute Working Paper Series, Report No. 16-114.

Pugh, S. D. (2001). Service with a smile: emotional contagion in the service encounter. Academy of Management Journal, 44, 10181027.

Richins, M. L. (1997). Measuring emotions in the consumption experience. Journal of Consumer Research, 24, 127-146.

Roberts, K. (2005). Lovemarks: the future beyond brands. New York: Powerhouse Books.

Roberts, R. J., \& Weerts, T. C. (1982). Cardiovascular responding during anger and fear imagery. Psychological Reports, 50, 219-230.

Roseman, I. J., Spindel, M. S., \& Jose, P. E. (1990). Appraisals of emotion-eliciting events: Testing a theory of discrete emotions. Journal of Personality and Social Psychology, 59, 899-915.

Roseman, I. J. (1991). Appraisal determinants of discrete emotions. Cognition \& Emotion, 5, 161-200.

Roseman, I. J. (1996). Appraisal determinants of emotions: constructing a more accurate and comprehensive theory. Cognition \& Emotion, 10, 241-278.

Russell, J. A. (1980). A circumplex model of affect. Journal of Personality and Social Psychology, 39, 1161-1178.

Russell, J. A. (2003). Core affect and the psychological construction of emotion. Psychological Review, 110, 145-172.

Russell, J. A., \& Feldman Barrett, L. (1999). Core affect, prototypical emotional episodes, and other things called emotion: dissecting the elephant. Journal of Personality and Social Psychology, 76, 805819.

Ruth, J. A., Brunel, F. F., \& Otner, C. C. (2002). Linking thoughts to feelings: investigating cognitive appraisals and consumption emotions in a mixed-emotions context. Journal of the Academy of Marketing Science, 30, 44-58.

Schachter, J. (1957). Pain, fear, and anger in hypertensives and normotensives: a psychophysiological study. Psychosomatic Medicine, 19, $17-29$.

Scherer, K. R., \& Moors, A. (2019). The emotion process: event appraisal and component differentiation. Annual Review of Psychology, 70, 719-745.

Schwartz, G. E., Weinberger, D. A., \& Singer, J. A. (1981). Cardiovascular differentiation of happiness, sadness, anger, and fear following imagery and exercise. Psychosomatic Medicine, 43, 343-364.

Schwarz, N., \& Clore, G. L. (1983). Mood, misattribution, and judgments of well-being: informative and directive functions of affective states. Journal of Personality and Social Psychology, 45, 513-523.

Shiota, M. N., Campos, B., Oveis, C., Hertenstein, M. J., Simon-Thomas, E., \& Keltner, D. (2017). Beyond happiness: building a science of discrete positive emotions. American Psychologist, 72, 617-643.

Skowronski, J. J., \& Carlston, D. E. (1989). Negativity and extremity biases in impression formation: a review of explanations. Psychological Bulletin, 105, 131-142.

Smith, C. A., \& Ellsworth, P. C. (1985). Patterns of cognitive appraisal in emotion. Journal of Personality and Social Psychology, 48, $813-838$. 
So, J., Achar, C., Han, D., Agrawal, N., \& Duhachek, A. (2015). The psychology of appraisal: specific emotions and decision-making. Journal of Consumer Psychology, 25, 359-371.

Srinivasan, S., Vanhuele, M., \& Pauwels, K. (2010). Mind-set metrics in market response models: an integrative approach. Journal of Marketing Research, 47, 672-684.

Stemmler, G. (1989). The autonomic differentiation of emotions revisited: convergent and discriminant validation. Psychophysiology, 26, 617-632.

Tax, S. S., Brown, S. W., \& Chandrashekaran, M. (1998). Customer evaluations of service complaint experiences: implications for relationship marketing. Journal of Marketing, 62, 60-76.

Taylor, S. E. (1991). Asymmetrical effects of positive and negative events: the mobilization-minimization hypothesis. Psychological Bulletin, 110, 67-85.

Tiedens, L. Z., \& Linton, S. (2001). Judgment under emotional certainty and uncertainty: the effects of specific emotions on information processing. Journal of Personality and Social Psychology, 81, 973-988.

Tsai, W., \& Huang, Y. M. (2002). Mechanisms linking employee affecting delivery and customer behavioral intentions. Journal of Applied Psychology, 87, 1001-1008.

Van Dijk, W. W., \& Zeelenberg, M. (2002). Investigating the appraisal patterns of regret and disappointment. Motivation and Emotion, 26, $321-331$.

Voorhees, C. M., Fombelle, P. W., Gregoire, Y., Bone, S., Gustafsson, A., Sousa, R., \& Walkowiak, T. (2017). Service encounters, experiences and the customer journey: defining the field and a call to expand our lens. Journal of Business Research, 79, 269-280.
Wallbott, H. G. (1998). Bodily expression of emotion. European Journal of Social Psychology, 28, 879-896.

Waterhouse, D. (2017). 4 stats that prove the power of emotions in sports advertising. https://unruly.co/blog/article/2017/06/21/statsemotions-sports-advertising/. Accessed 27 March 2018.

Watson, D., Clark, L. A., \& Tellegen, A. (1988). Development and validation of brief measures of positive and negative affect: the PANAS scales. Journal of Personality and Social Psychology, 54, 1063-1070.

Watson, G., Beck, J., Henderson, C., \& Palmatier, R. (2015). Building, measuring, and profiting from customer loyalty. Journal of the Academy of Marketing Science, 43, 790-825.

Webster, F. E. (1995). Industrial marketing strategy. Etobicoke: Wiley.

Yen, H. R., \& Chuang, S. (2008). The effect of incidental affect on preference for the status quo. Journal of the Academy of Marketing Science, 36, 522-537.

Yih, J., Uusberg, A., Taxer, J. L., \& Gross, J. J. (2019). Better together: a unified perspective on appraisal and emotion regulation. Cognition and Emotion, 33, 1-7.

Zeelenberg, M., Nelissen, R. M. A., Breugelmans, S. M., \& Pieters, R. (2008). On emotion specificity in decision making: why feeling is for doing. Judgment and Decision making, 3, 18-27.

Zeithaml, V. A. (1981). How consumer evaluation processes differ between goods and services. In: Proceedings of the American Marketing Association First Services Marketing Conference (pp. 186-190).

Publisher's note Springer Nature remains neutral with regard to jurisdictional claims in published maps and institutional affiliations. 